Review Article

\title{
Review on Unmanned Underwater Robotics, Structure Designs, Materials, Sensors, Actuators, and Navigation Control
}

\author{
Javier Neira, Cristhel Sequeiros, Richard Huamani, Elfer Machaca, \\ Paola Fonseca, and Wilder Nina
}

Veox Inc., Arequipa, Peru

Correspondence should be addressed to Wilder Nina; wnina@veox.tech

Received 21 February 2021; Accepted 7 June 2021; Published 6 July 2021

Academic Editor: L. Fortuna

Copyright (c) 2021 Javier Neira et al. This is an open access article distributed under the Creative Commons Attribution License, which permits unrestricted use, distribution, and reproduction in any medium, provided the original work is properly cited.

\begin{abstract}
Since its beginning, around the 50s decade, until present days, the area of unmanned underwater vehicles (UUV) has considerably grown through time; those have been used for many tasks and applications, from bomb searching and recovery to sea exploration. Initially, these robots were used mainly for military and scientific purposes. However, nowadays, they are very much extended into civils, and it is not hard to find them being used for recreation. In this context, the present research is an effort to make a walkthrough of evolution in this area, showing a diversity of structure designs, used materials, sensor and instrumentation technologies, kinds and the number of actuators employed, navigation control techniques, and what is new in development trends. The paper gives a clear starting point for those who are initializing into this research area; also, it brings some helpful knowledge for those who already have experience.
\end{abstract}

\section{Introduction}

Robotics is a branch of engineering that involves the concept, design, manufacture, and operation of programmable machines, which can develop their autonomy in the execution of a specific task. Submarine robotics can be subdivided as shown in Figure 1, where one can identify those related to underwater robotics (unmanned water vehicles). Underwater robotics have been developed for decades, and they were characterized by manned water vehicles development. However, in the last decades, due to the cost demanded by the construction and use of these vehicles, researchers led to the development of robots or unmanned underwater vehicles (UUV), where each time the robots were optimized and used in a wide variety of applications for the benefit and sustainable development of the planet. Since there is an immense magnitude of the oceans and due to the human difficulty for their exploration, the vast majority of them have not yet been explored (two-thirds of the planet) and around $37 \%$ of the world's population is less than 100 kilometres from the ocean [1]. This means that knowledge of the marine environment has and will continue to have an impact on the future survival of humanity. That is why researchers have strived to develop unmanned vehicles that are increasingly efficient and can provide work and maintenance services underwater, as well as explorations of ever deeper marine environments. For example, there are an estimated 2 billion tons of manganese nodules in the Pacific Ocean near the Hawaiian Islands [2].

The UUVs are identified in Figure 1. Mainly, they are subdivided into those that are remotely operated (ROV) and those that are autonomous (AUV). The ROV is a vehicle joined to an umbilical cable, and, according to its application, it can be classified into observation, work, and special purpose $[3,4]$. ROVs play a vital role in military operations (e.g., torpedo and mine recovery), rescue operations (e.g., locating historic shipwrecks, such as the RMS Titanic), and critical oil and gas operations. In recent years, the range of vehicles and mimitizing the need for human operators have increased due to research efforts. However, we have autonomous vehicles (AUVs); these are indispensable tools, mainly for ocean exploration tasks. They are built using various high-end technologies and equipped with several of them $[5,6]$. During the subsea exploration process, the AUV 


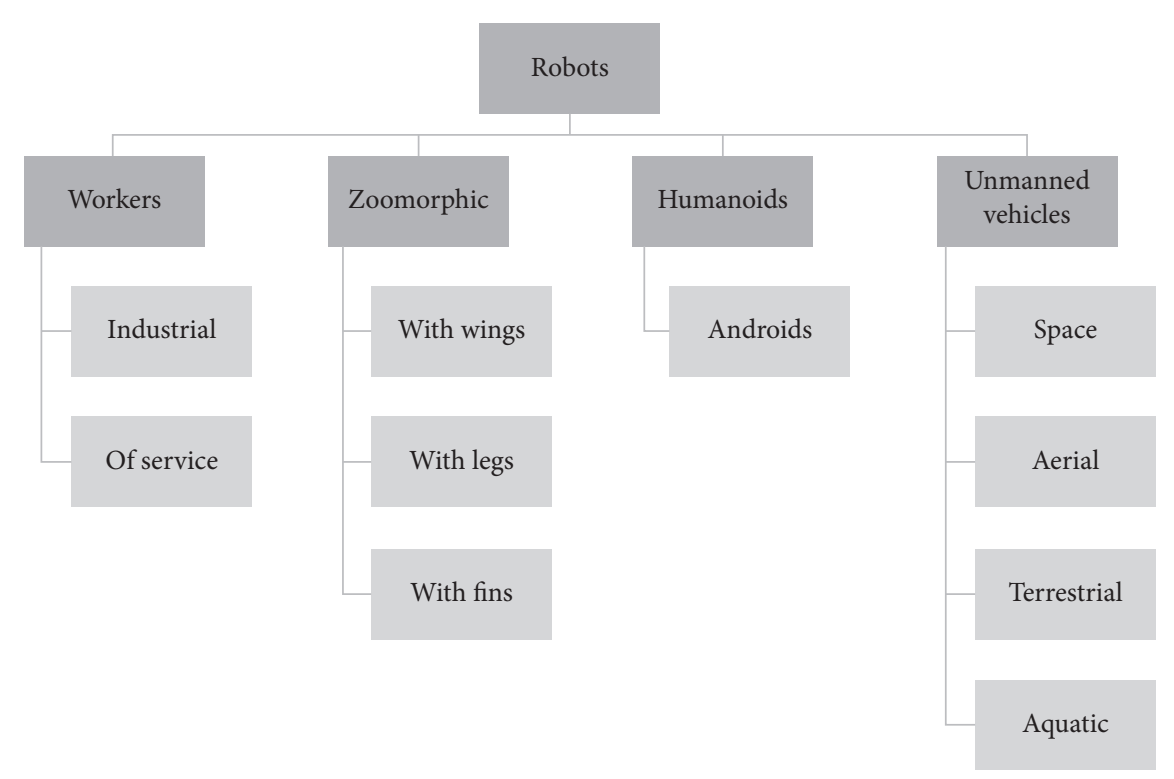

Figure 1: Location of unmanned water vehicles within a basic robotics classification.

performs necessary maintenance and repairs, transports the necessary equipment, and monitors and records different situations under exploration. In oceanographic research, the AUV may be used in various measurements; one of them is for the observation, release, and recovery of instruments related to the monitoring of submarine volcanoes, in addition to carrying out surveys of the seabed and various studies in areas such as biology and hydrology.

The unmanned vehicles' structural designs have been based on their shape, actuators' distribution, and materials used. They include monitoring and measurement tasks of oceanographic variables and navigation of the UUV; to achieve these objectives, it will be necessary to have a diversity of sensors. Everything presented is the subject of analysis in this article. This article is structured as follows: Section 2analyzes the morphologies used which are characterized by their type of hull and geometric shape and those that are bioinspired; additionally, it considers the distribution of propellants, materials used, and hermeticity. Section 3presents the instrumentation and actuation elements used interchangeably in ROVs and AUVs. Section 4analyzes the navigation, orientation, and movement's control of both ROVs and AUVs. Finally, the conclusions of this work are presented in Section 5.

\section{Structural Designs and Used Materials}

2.1. Morphologies. The morphological review refers to underwater robots' geometrical shape, which is dependent on many factors like internal electronic devices distribution, sensor, motors, structure stability, and drag coefficient defined to move the robot, among others. Additionally, it must take the robot's degrees of freedom into account, since this is needed to locate motors in the structure correctly.

This kind of robot does not necessarily have a geometrical shape; there are many ROVs and AUVs with biomimetic structure; That is to say, they try to mimic aquatic animal's movements, such as jellyfishes, stingrays, and sharks. Even though underwater robots that use thrusters with symmetrical geometric shapes are generally more efficient, many works in bioinspired robots are being developed and continue looking to increase knowledge in this study area.

2.2. By Hull Type. Some robots work underwater; those are of two hull types, open and close. The open ones generally have a hermetic box that is over a frame, and the other components like engines, buoyancy elements, sensors, and lights are over it too, while the closest ones have a bigger case that covers all elements; they do not have a frame because all elements are inside of the case. The prototypes or designs which have a close hull usually have a cylindrical or round geometric shapes; for example, there are some which look like a torpedo or a sphere.

2.3. By Geometric Shape. One of the most famous shapes of underwater robots is the cylindrical shape, and on the top they have the appearance of a dome, which means they look like a torpedo. In 1973, one of the first portable ROVs was made, and it had a torpedo shape as shown in Figure 2.

The robot was hydraulically controlled from the surface, and it began to be controlled with electricity. That was the main reason of its popularity, ten years later, 500 prototypes were sold. Those kinds of shapes come from military technology developments like many other technological advances. In this specific situation, the form comes from torpedoes that were on military ships; this is the case of MK-38.

In the Applied Physics Laboratory of Washington University, some modifications to a torpedo were made, and it became an inspiration to create the REMUS robot in 1994 [8]; a schematic of such robot is shown in Figure 3.

The design was of a cylindrical shape, and it moved thanks to only one propeller behind the robot and four fins behind the propellers; two of them were located on a vertical 


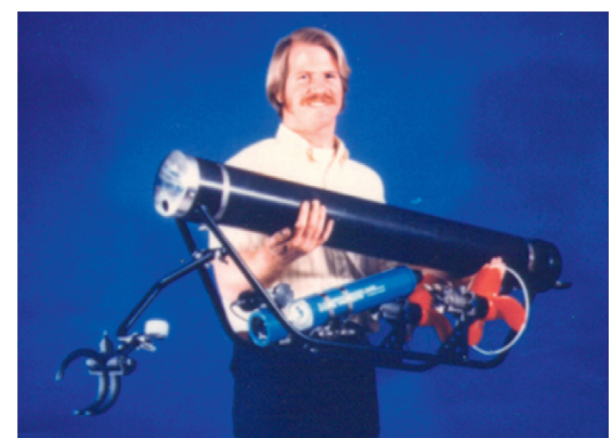

Figure 2: Snoopy ROV [7].

axis, and they had their drive mechanism like the ones that were located on a horizontal axis. They were there to give direction to the robot. The robot had a length of $114 \mathrm{~cm}$ with a diameter of $18 \mathrm{~cm}$ and a weight of $40 \mathrm{~kg}$. The torpedo shape is still used because of hydrodynamic advantages.

In 1997, the REMUS robot's development continued with one smaller model that a person could uphold and transport. The robot had a length of $134 \mathrm{~cm}$ with a diameter of $19 \mathrm{~cm}$ and a weight of $31 \mathrm{~kg}$. The robot had four fins as shown in Figure 4. The fins were in the stern, and they had an aerodynamic shape called NACA 0012. The fins moves were done using a pinion, a toothed chain, and an engine. Behind the fins was the propeller; all the system described gave the direction to the robot.

This torpedo-like shape allows underwater robots to move at high speeds on the horizontal axis, and they descend diagonally with the help of their fins. There are other kinds of underwater robots which have a torpedo shape, but they have more propellers and do not have rear fins; an example is the Nessi robot in its sixth version [10]. It was built for the SAUC-2011 competition, with $174 \mathrm{~cm}$ length and a diameter of $28 \mathrm{~cm}$. To be able to move underwater, it was equipped with six propellers: two for lateral motion, two for vertical and pitch moves, and two on the robot sides to control the forward and yaw moving. A picture of Nessi's sixth version can be seen in Figure 5.

Another development of a torpedo-shaped robot was made in 2017, which had many propellers, as shown in Figure 6, but this was bigger than others shown in this paper. It had $534 \mathrm{~cm}$ length, $62 \mathrm{~cm}$ diameter, and a weight of $380 \mathrm{~kg}$ [11]. It had five propellers: one located on the top, two on the extremes to immerse, and the last two across it to control yaw movements. If there were any troubles and the robot needed to come back to the surface, it had a ballast tank.

There were other investigations of more complex models, which had a torpedo shape; an example of the research was the development of a robot in 2018. It had four fins located on the sides including four propellers [12] and two propellers to immerse. The robot had a length of $140 \mathrm{~cm}$, a diameter of $20 \mathrm{~cm}$, and a weight of $32 \mathrm{~kg}$. Figure 7 shows the position of those elements. The robot was constructed to improve the propulsion system, which did not generate countless bubbles because it was a trouble for the front camera to see; for this reason, the design had two more propellers and it had four fins to go forward; the movement was based on the turtles' movement [13].
There are new studies that have been done during the last few years about different shapes of underwater robots. In comparison, those have advantages compared with traditional shapes, since their forms are symmetrical. In an investigation project, the goal was to control the position of the symmetrical robot in events of disturbances with a proportional change of the direction force from propellers; all their motors were inside of the closed hull. The design was developed in 2012, and it had a diameter of $40 \mathrm{~cm}$ and weighted $6.3 \mathrm{~kg}$. This spherical robot is shown in Figure 8.

The assembly of the mechanical components which are inside of the robot was made manually, and it caused troubles in the robot's operation underwater because the robot was less stable, and it could not move for long periods. Figure 9 shows some of the improvements made with a 3D printer to fabricate the mechanism for the water jets [15]. The robot has two servomotors and a water jet in each leg. For its movements, one servomotor is first turned vertically to lift the propeller of the water jet; then, the horizontal servomotor moves the propeller of the water jet to go forward; subsequently, the water jet drops vertically; finally the robot swings to take a step.

There is another way to get easy access to the robot's components; those kinds of ROVs are used to have a square or rectangular frame, and some components lay over the frame, such as hermetic boxes, lights, propellers, and other devices. The robot called CURV [7] was one of the first to implement the distribution mentioned. It was designed by the US Navy to recover lost bombs or torpedoes; in one of its missions, in 1966, the ROV was able to immerse up to $869 \mathrm{~m}$; it was more than the maximum depth the robot could achieve according to its design; in addition to this, it operates under positive buoyancy, which means that if its propellers were turned off, the robot was going to the surface automatically. The robot is still working with some improvements, and it is sent to different missions; Figure 10 shows the robot CURV II that is similar to CURV. In Figure 10, it is possible to appreciate the ROV size compared with a person's size. Therefore, it was necessary to use a pulley on the boat to place it on the water.

With the passing of the years, underwater vehicles which have similar shapes to CURV have been developed for subsea exploration and they can be carried by one person due to their smaller form. An ROV with a similar appearance to that of CURV was developed in 2010; the robot was called Nessie IV [16], and it had a rectangular shape, aluminum frame, two hermetic chambers over the frame with a diameter of $22 \mathrm{~cm}$, sensors, and some safety components.

One of the hermetic cameras had the motors and drivers' electric connections and batteries; the other had sensors interfaces and batteries electric connections. The robot worked using five propellers: two of them were vertically located to control depth and pitch, two others were located on the sides to control forward and yaw moves, and the last one was over the vertical axis to guide translation over this axis. The Nessie ROV shown in Figure 11 was an evolution of past versions and it was made to participate in a competition known as "SAUC-E" where it was the winner robot. 


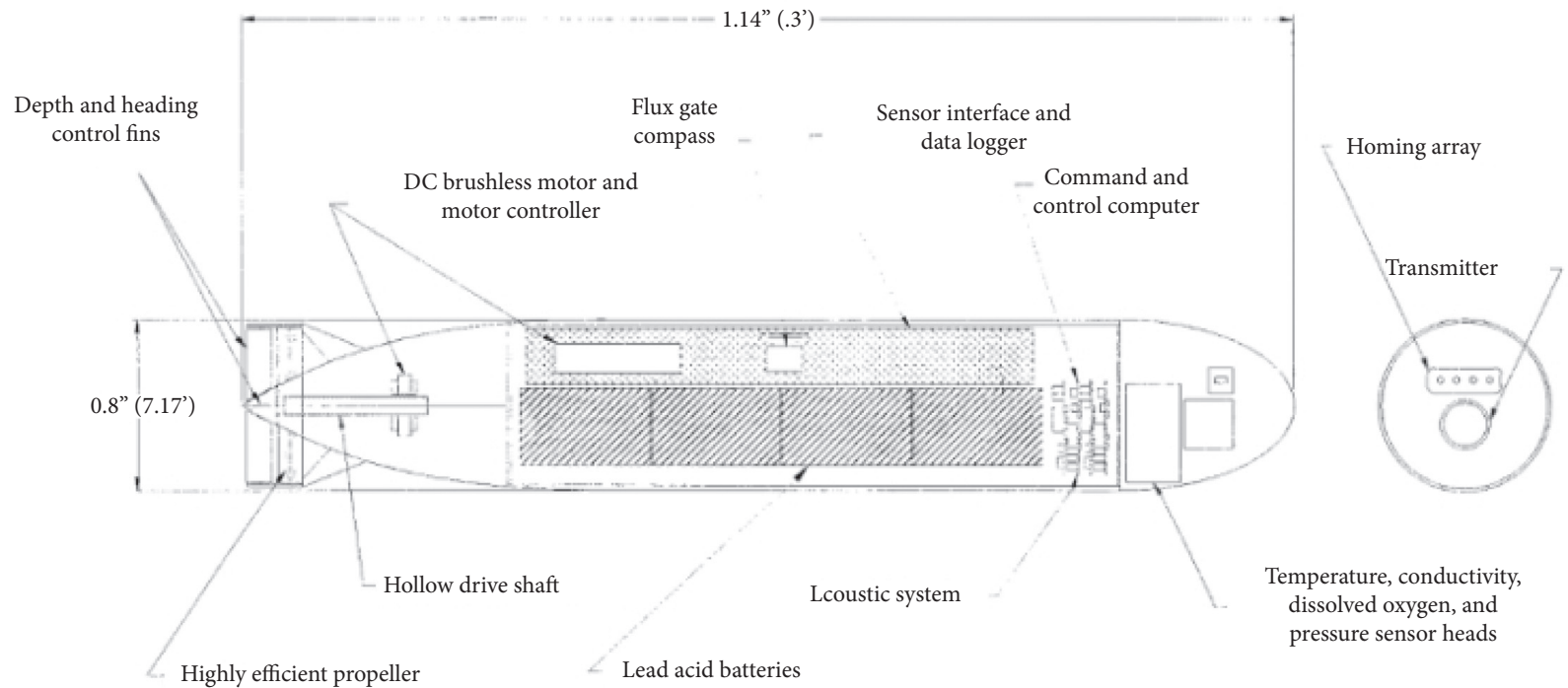

Figure 3: REMUS (1994) [8].

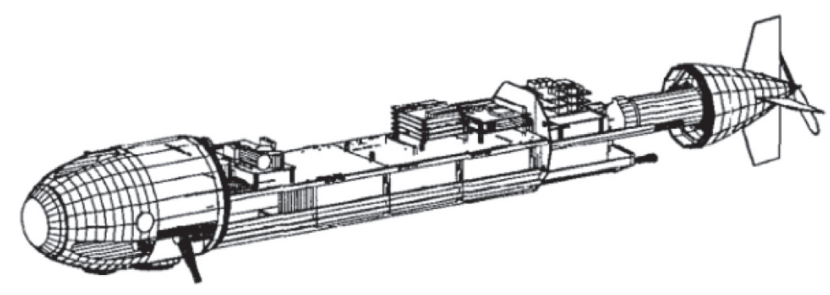

Figure 4: REMUS (1997) [9].

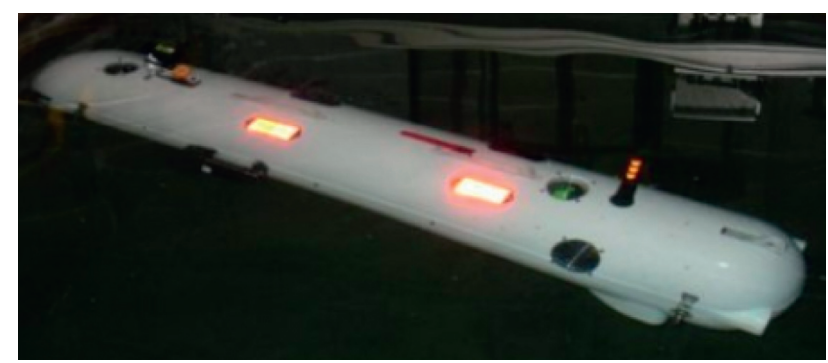

Figure 5: Nessi (2011) [10].

Some ROVs have cubic-like frames such as CISCREA that is shown in Figure 12. It had six propellers: four of them were outside of the vehicle's longitudinal axis, which gave the robot a better turning moment, more lengthwise stability, and better movements over the horizontal axis, and the other two were to control depth. The robot had a length of $52.2 \mathrm{~cm}$, a width of $40.6 \mathrm{~cm}$, a height of $39.5 \mathrm{~cm}$, and a weight of $22 \mathrm{~kg}$ [18].

Some ROVs have been developed, having a frame to support their components as the ones mentioned; one of them was a robot called DaryaBird that was developed in 2016; it was made to participate in a competition for underwater robots, and one of its hermetic sections had a torpedo shape. Over the frames were some elements such as its gripper, that is, a mechanical hand to carry objects, a battery, a pneumatic tank, and its hermetic chambers.

It had $83 \mathrm{~cm}$ length, $50.6 \mathrm{~cm}$ width, $41.3 \mathrm{~cm}$ height, and $32 \mathrm{~kg}$ weight [19]. It had six propellers; two were to control depth and roll and the other four were located to allow forward movements, yaw, and translation over the vertical axis. Figure 13 shows the robot DaryaBird, showing the propellers distribution where they are approximated to $45^{\circ}$ over travel axis forward.

There was a design proposed in 2019 which had a rectangular shape and positive buoyancy; this investigation [20] was more about the mechanic design, the design features to achieve stability, and a CFD analysis of its final shape. The robot had two pipes on the top from 2 to 4 inches, respectively, and a frame made of aluminum which supported the ROV's elements. The structure guaranteed stability due to the location of the mass center in the design, which was under the buoyancy center. The top pipes were located there to obtain better stability while the robot rolled and to get the buoyancy center of the robot nearer to the top, as is shown in Figure 14. The proposed design aligned mass center and buoyancy center over the horizontal axis to the movements on pitch and yaw could be easier.

Due to the fact that the mass center and buoyancy center were not aligned over the vertical axis, the immersion propellers were distributed to get a pitch control as is shown in Figure 15.

There was a robot proposed in 2019 to work in shallow waters [21]; it had a cubic shape, and its principal structure was anticollision. The robot's design had an acrylic plate on the front of it to locate a camera. Two propellers controlled the forward and yaw movements. The force given by the propellers should be designed greater than $1 \mathrm{~kg}$ and the immersion propellers should be between $2 \mathrm{~kg}$ and $8 \mathrm{~kg}$. The robot was designed to have a hermetic chamber just for the battery and another for electronic parts; Figure 16 shows the final design with all its parts.

2.4. Bioinspired. In the last decades, there has been a lot of interest in improving the performance of underwater robots by taking a bioinspired optimization approach in aquatic 


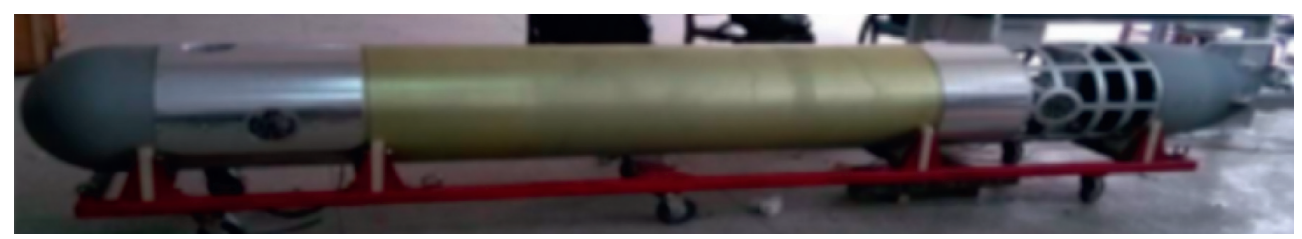

FiguRE 6: Large torpedo [11].

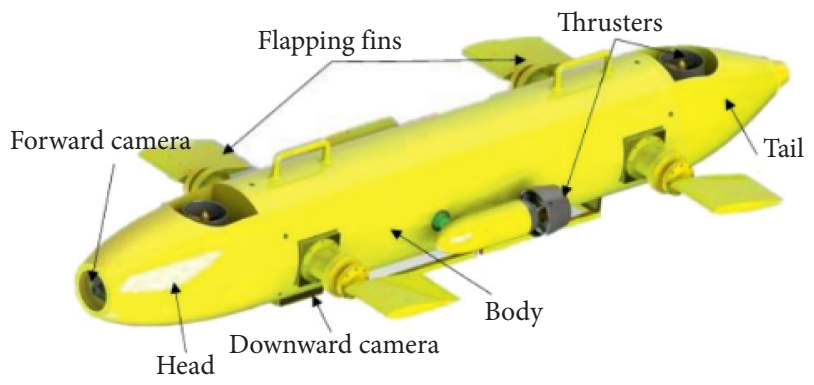

Figure 7: Hybrid (2018) [12].

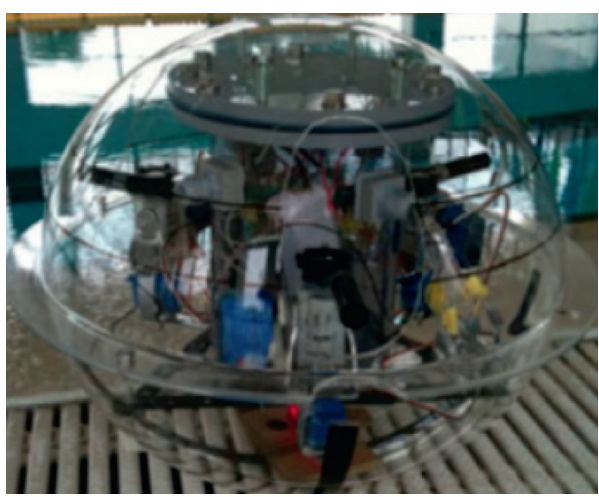

Figure 8: Sphere (2012) [14].

animals, which after natural selection have evolved due to their habitat to the point of having physical characteristics and excellent morphology.

In 2012, a review of different biologically inspired underwater robots presented and addressed a key problem in them, mentioned in [22], which is to achieve adequate movement in real environmental conditions and classification of robots by their way of swimming, which can be seen in Figure 17. The proposal presented for the problem was the use of intelligent actuators, which are a viable alternative to be able to achieve the flexible and complex movements that a camouflaged robot requires without the need for additional parts.

The smart actuators are classified on shape memory alloy (SMA), ionic polymer-metal compound (IPMC), and a mix between SMA and IPMC. Usually, the materials are combined with other materials; an example of this is presented in Figure 18. This embedding gives better mechanical features for robots.

Normally, for the creation of parts of a bioinspired robot, it is necessary to use polymers together with the alloys presented above, which serve to simulate elasticity and deformability to achieve complex shapes of the living being to be mimicked.
The union of soft and low rigidity materials with intelligent actuators is called smart soft composites (SSC); its manufacture is carried out through the use of multinozzled 3D printer, for this UV curable polydimethylsiloxane (PDMS) is used, which can be $3 \mathrm{D}$ printed by direct ink writing (DIW) or stereolithography (SLA), where cables, connections, communication modules, batteries, and intelligent actuators or anisotropic materials are placed layer by layer in the final prints $[23,24]$. See Figure 19.

In the use of these technologies, a new low-cost printing method is presented in [25], where printing tests were carried out, and a material switcher PDMS was developed from laser diffraction thanks to the use of a $T$ union by two currents: air and a second fluid (water or oil); it should be noted that they do not use mirrors or lenses that are normally in stereolithography (SLA).

Although some robots are made based on these intelligent actuators, their movement speed is slow and limited compared to the living beings from which the inspiration was obtained or robots that use conventional actuators, since these have the advantage of being more compact, in addition to achieving better mimicry and acquiring important biological characteristics, which are what they were looking for.

A robot with a dolphin shape was made in 2016 [26]; it was an autonomous underwater vehicle (AUV) developed to measure water quality with a biomimetic system. The prototype is shown in Figure 20, and the design was inspired by an orca. They were looking to mimic the high hydrodynamic and stability performance of an orca, because the evolution of those animals has allowed them to develop those features correctly. The dolphin could mimic some peculiarities on an orca and it could monitor and move in difficult environments.

The robot's design had a rigid head, a hollow shell to the components, a cabinet for the waist joint, and a chamber for the caudal joint. It had a hydrodynamic shape to reduce the drag force, its waist was joint to get the necessary thrust to move, and a dorsal fin and pectoral fins to improve stability also allowed performance turning manoeuvres. In the same year, a mechanical design of an autonomous vehicle (AUV) was presented inspired by a shark that had a vision system to take the information of the underwater environment, for future applications as monitoring, searching objects, and trajectory tracking.

The shark robot's structure is shown in Figure 21 and it had two main principal parts.

On the front was a rigid body with an aerodynamic contour of a shark to get better performance swimming and two pectoral fins to make movements as diving, emerging, and swinging. Further, it had space where there were parts 


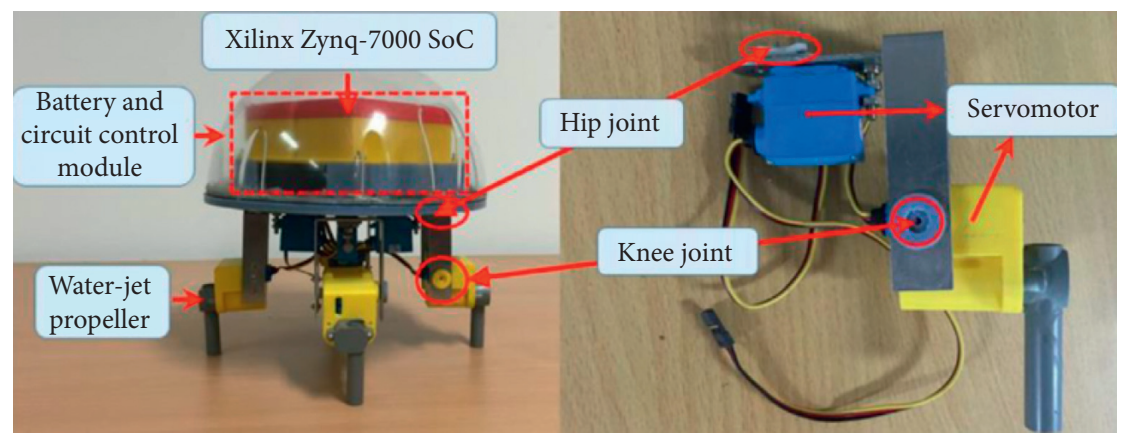

Figure 9: Sphere (2014) [15].

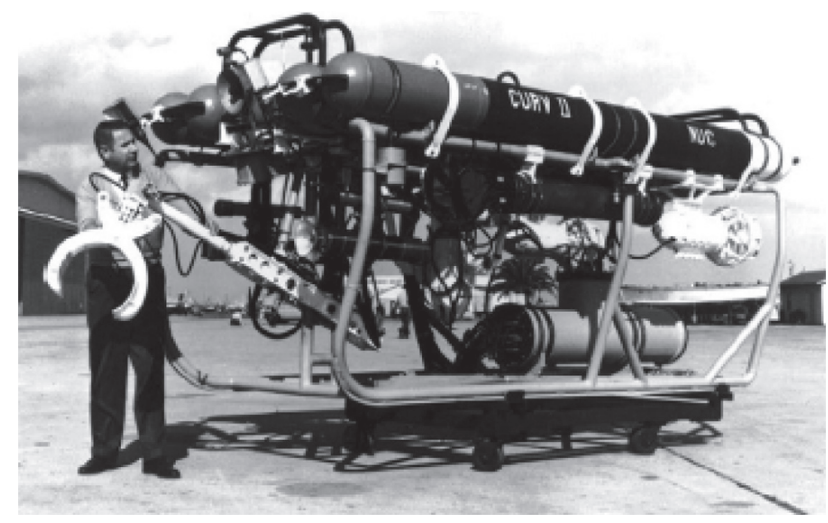

FIgURE 10: CURV II [7].

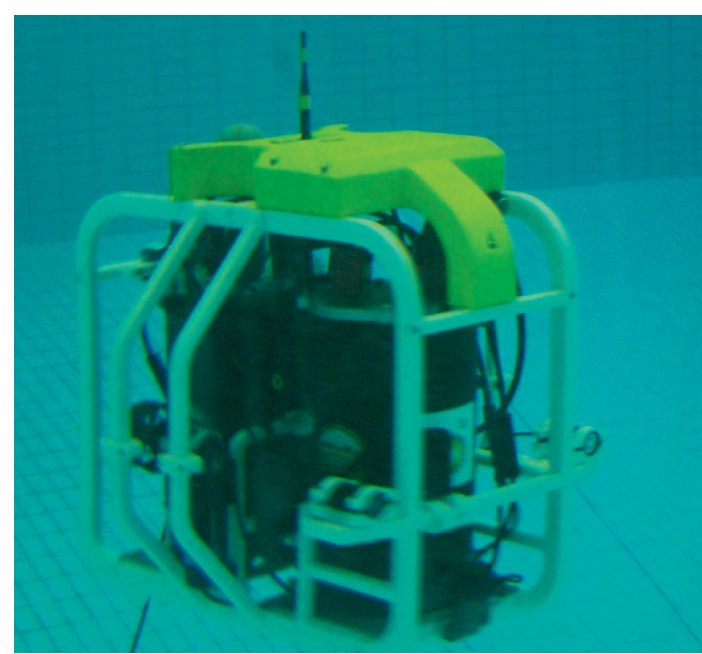

Figure 11: Nessie IV [17].

like cameras, circuits, sensors, and batteries. On the back was a multiarticulated body with three servomotors connected with an aluminum structure that allowed better movements when turning and achieved more manoeuvrability and thrust.

The shell was made of ABS, and it had $482 \mathrm{~mm}$ length, $208 \mathrm{~mm}$ width, $125 \mathrm{~mm}$ height, and $1.3 \mathrm{~kg}$ weight [27]. The robot used two impermeable systems: the first one for the top where there was a removable chamber that was a seal with a fluoride rubber gasket and the second for pectoral fins

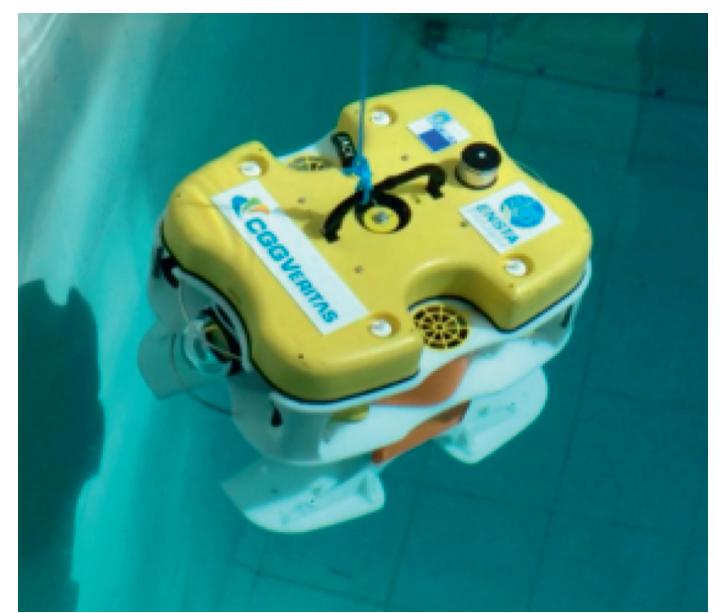

Figure 12: CISCREA [18].

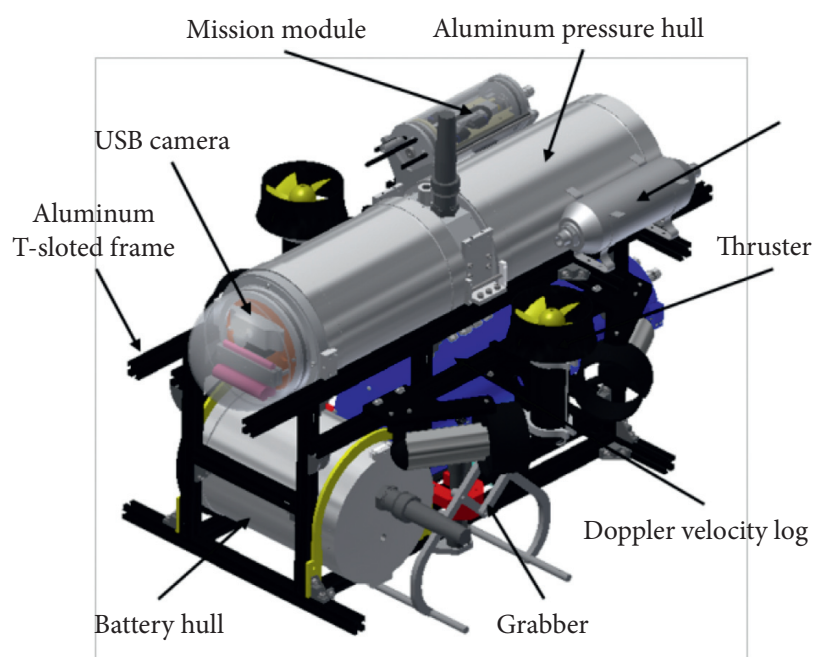

FIgure 13: DaryaBird [19].

because they had a gyratory axis with a bearing and a Glyd Ring; they needed a dynamic seal in each fin. There was an underwater manipulator which was built inspired by a snake. The robot's purpose was to make exploration activities and intervene in underwater infrastructures, thanks to its shape, which gave flexibility and the ability to get into 


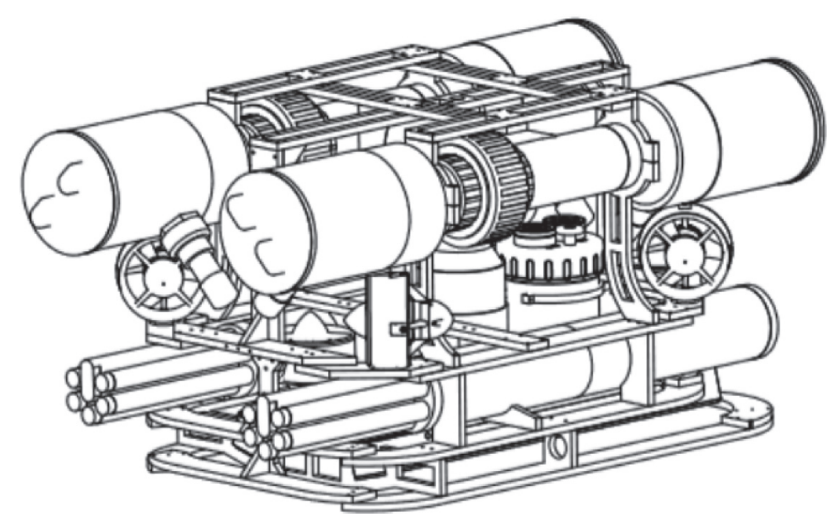

FIgURE 14: Mechanical design of a rectangular ROV [20].

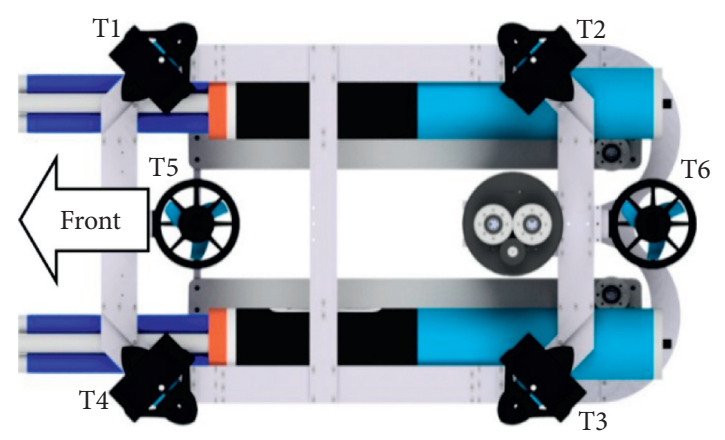

FIGURE 15: Mechanical design of a rectangular ROV [20].

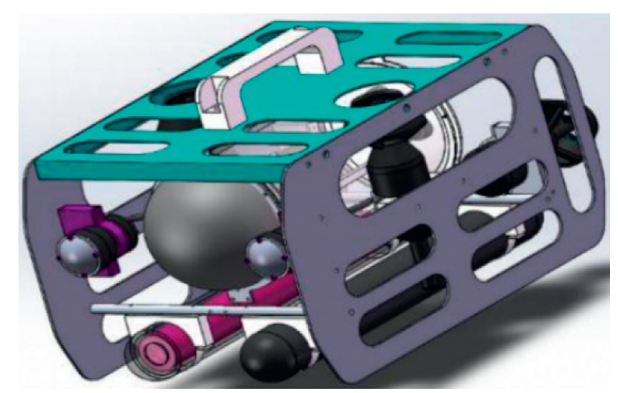

FIgURE 16: Underwater robot for shallow depth [21].

difficult spaces. The robot was designed by the University of Science and Technology of Norway.

The robot is in the category of AUV and it had a serial link mechanism with different modules, which had tunnel thrusters and a stern thruster to move forward. Further, if needed, the robot could mimic the swimming of an eel due to good flexibility. The prototype is shown in Figure 22. The design was submitted on a very complex simulation environment with Matlab, which allowed to coordinate different actuators on the articulations, getting good results of the proposed design, evidencing that the simulation environment developed had high potential for this kind of tests [28]. The robot OpenROV was an open code ROV developed in 2019 with a bioinspired focus; it was made for the City University of Applied Sciences in Bremen; its work was focused more on getting better stability, reducing the drag force, and evaluating alternative thrust systems [29].
The shell optimization was done differently on typical applications identifying the appropriate parameters to modify and improve with a biological model that meets the needs. For the selected models, simulations were done in a scalar level $(1: 3)$ inside of an air chamber. A better structure under the drag was implemented on a functional level $(1: 1)$ to do a test on water and the designs that have passed by CFD simulations to get better data. The other focus was the implementation of an alternative thrust system based on biological moves of fins in the fish. The better models were selected and made with a 3D printer; they were put to the test and, finally, the one that had a better performance was determined. The implementation of the system is shown in Figure 23.

The experimental results showed a drag force reduction between $50 \%$ and $85 \%$ in case of comparison to the basic OpenROV and the thruster system; although they were not that efficient as the thrusters, they were better on the flexibility, frequency, and amplitude. In 2019, another design of a robot called "CasiTuna" was inspired by tuna, a fish capable of high-velocity movements and manoeuvrability; additionally, it can swim huge distances.

The robot tried to mimic the features of tuna, focusing on three main aspects; the first one was a rigid body in the front where the electronic systems and a new thruster system of two engines exist, something that was not common on those kinds of robots due to the quantity and the position. They are accompanied by dorsal fins and an internal system to adjust the buoyancy. The second main point was a lightweight body on the back; the section had two articulates, and, to achieve the movements, it had a mechanical system of 4 bars and a group of bevel gears that avoid involuntary ripples thanks to the new position of the engines. The third main aspect was a rigid tail fin that allowed it to generate greater thrust. The robot "CasiTuna" is shown in Figure 24.

The robot had $520 \mathrm{~mm}$ length, $100 \mathrm{~mm}$ width, $130 \mathrm{~mm}$ height, and $2.6 \mathrm{~kg}$ weight; principally, its materials were ABS and PP. The robot went through simulations in ADAMS and tests underwater validating design's effectiveness focus on displacement speed and stability, due to its aerodynamic shape. Table 1 shows some features of the mentioned robots.

2.5. Thruster Distribution. The thruster's location and the quantity depend on with how many degrees of freedom the robot is going to be designed; there is a case where, to achieve all degrees of freedom, the thrusters have actuators to move them and change the direction of the force.

An ROV had five thrusters; some actuators on them were designed in 2015; two thrusters were located on the extremes to move over the horizontal axis and yaw movements, and the other thrusters located on the sides had a servomotor; each one has the objective of changing the direction force and controlling roll movements as pitch and yaw, but they were employed to immerse [31]. The last thruster was designed to operate all time and get stability on pitch movements. The thrusters are shown in Figure 25.

The underwater robots must have an emerge and immerse system for that reason; they use thrusters to do those 


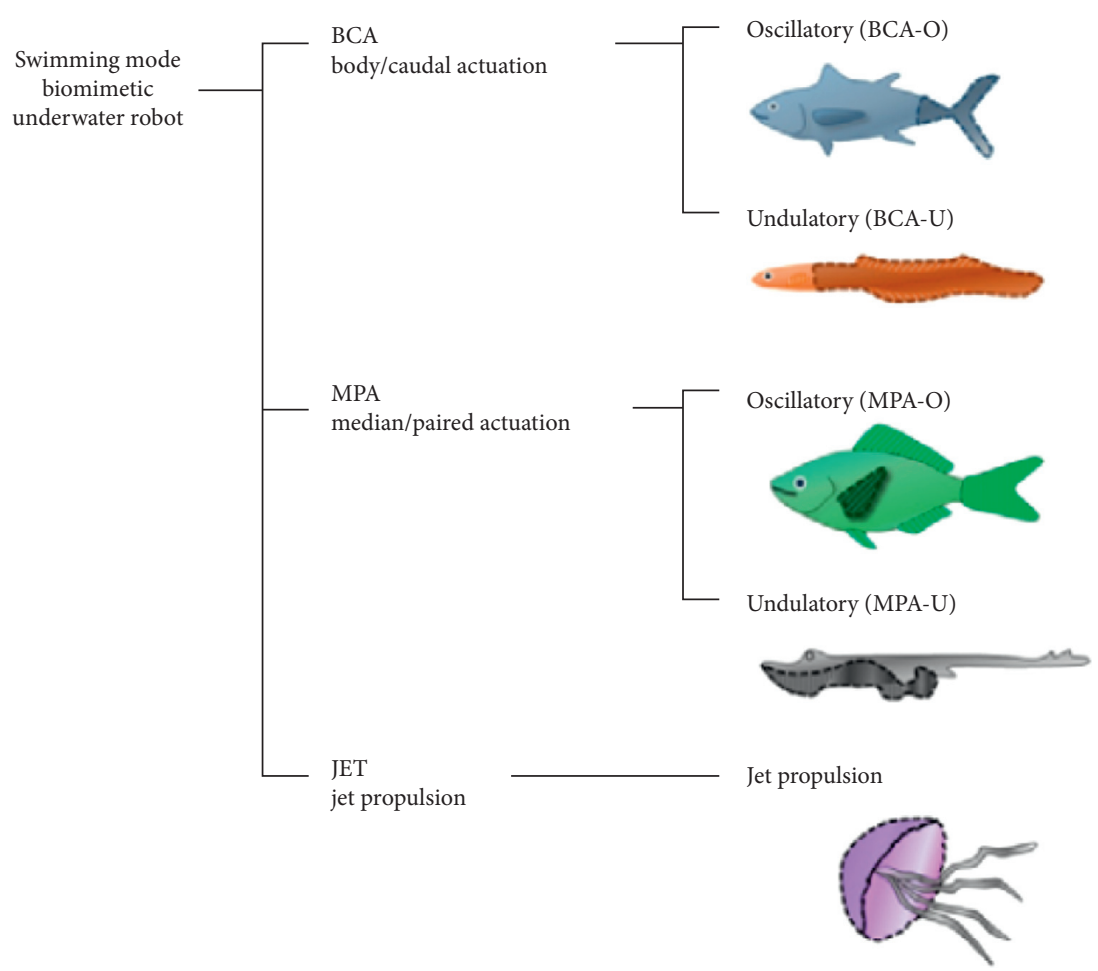

FIGURE 17: Classification of bioinspired robots by their swimming mode [22].

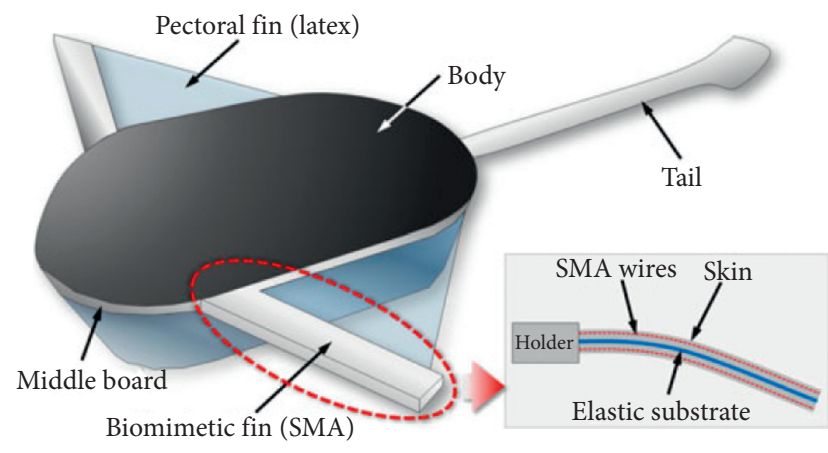

Figure 18: Manta ray robot [22].

tasks or implement a ballast tank. There was a robot developed for investigation purposes by Norway in 2017; it had three thrusters for the robot's movements underwater. The prototype is shown in Figure 26.

The objective of the ROV mentioned in Figure 26 was the development of a low-cost robot to monitor fishes for aquaculture [32]. The thrusters were around a cylinder placed $120^{\circ}$ from one another; this allowed them to move in two dimensions. The robot had negative buoyancy. To control its depth, it had a rope attached to a platform on the surface. The robot's stability had better control due to the prototypes' symmetry; therefore, the pitch and roll caused by the pendulum effect were not affected. In 2019, a design was proposed for aquaculture applications; the shape and thrusters were located to avoid lurching effect, which means that a buoyancy object loses its stability due to a strong water stream. Figure 27 shows assembled robots and in Figure 28 it is possible to see locations of their four thrusters, which gave them 5 degrees of freedom [33].

There was another research where the robot's shape had more DOFs (degrees of freedom) than other distributions, besides having just four engines as is shown in Figure 29. The thrusters are distributed vertically and horizontally; the difference in forces between each pair allows the robot to have more degrees of freedom. For example, if the motor above has more force than the one below, the robot will be able to change direction achieving a $90^{\circ}$ turn [34].

The robot shown in Figure 30 was employed in research for the best control system for a robot of this type according to the mathematical model obtained by a CFD program [35]. The robot had six thrusters: two of them were applied to dive and the other four located out of the longitudinal axis were approximately $45^{\circ}$ concerning the forward axis. The roll and pitch did not need to be controlled because the distribution element gave enough stability to those degrees of freedoms.

There are robots with more than five thrusters. The robot shown in Figure 31 had eight thrusters, which allowed the robot to move on 6 degrees of freedom, like with six thrusters, but giving the advantage of more thrust to dive.

Figure 31 is an upgrade of Bluerobotics' ROV [36], with eight thrusters: four of them were locatedvertically outside the frame with an external protection to prevent the propellers from being damaged during their operation or the tether cable can be tangled or damaging one of themwhile they are working or tethered could tangle and damage on them. The thrusters were placed in the same position as the original Bluerobotics' ROV. 


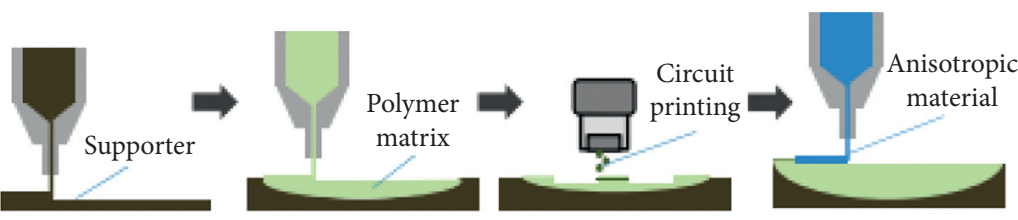

(a) Supporter deposition

(b) Part deposition

(c) Circuit printing

(d) Deposition of

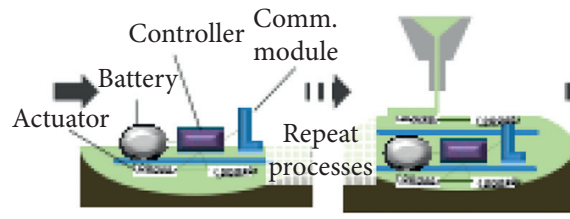

anisotropic materials

(e) Component

(f) Part deposition
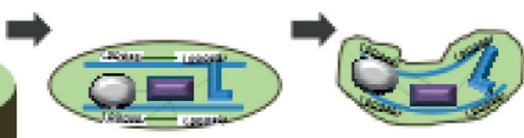
embedment

(g) Support removal

(h) Soft morphing of robot/structure

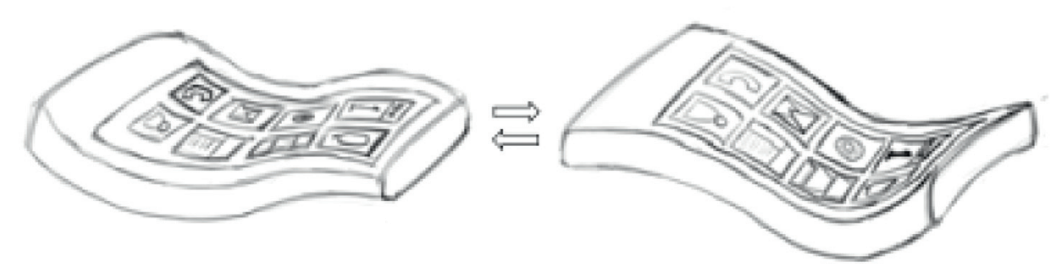

FIGURE 19: SSC manufacturing process [23].

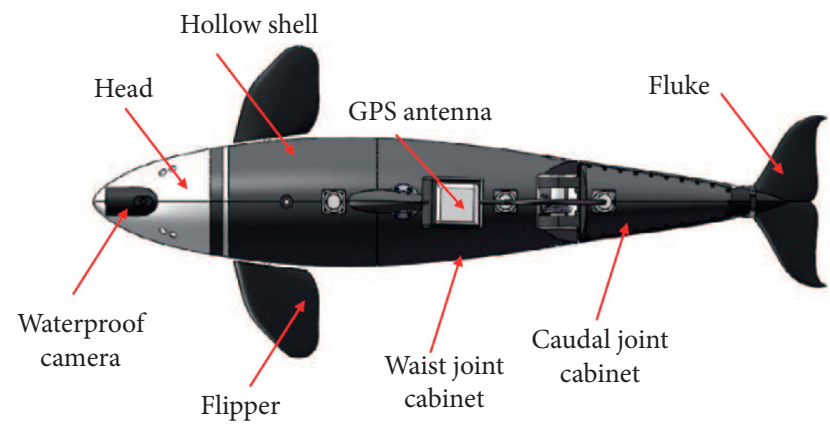

Figure 20: Dolphin (2016) [26].

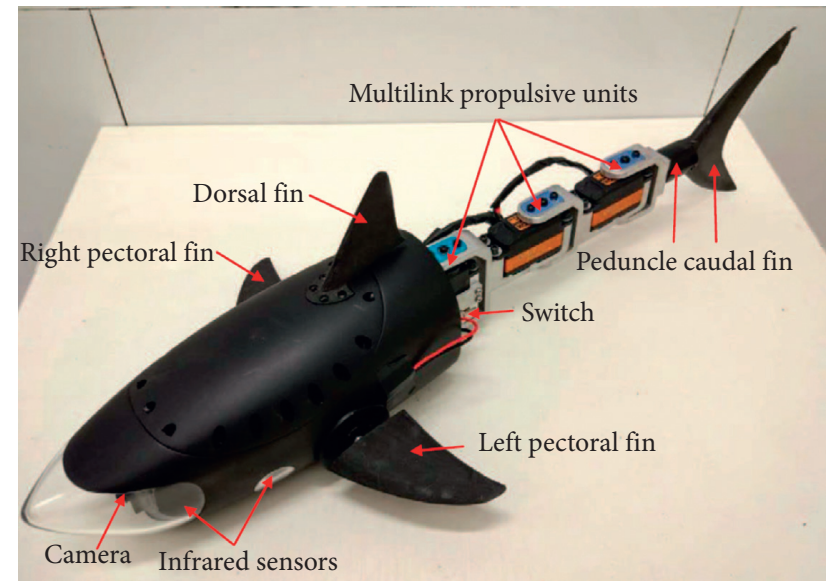

Figure 21: Shark robot prototype (2016) [27].

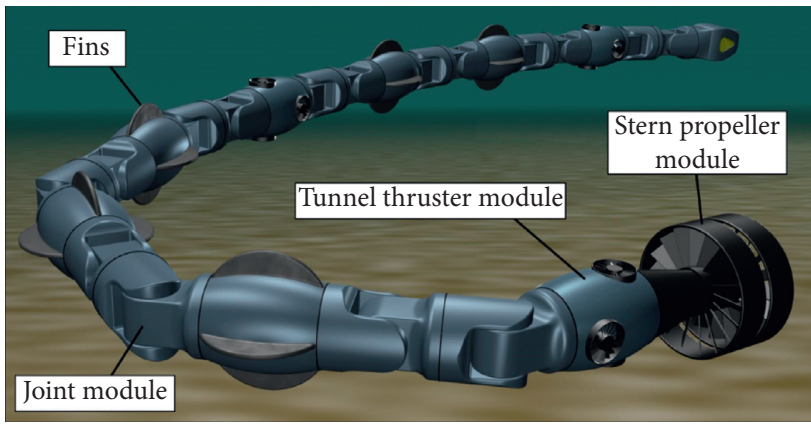

FIgURE 22: Underwater manipulator design (2016) [28].

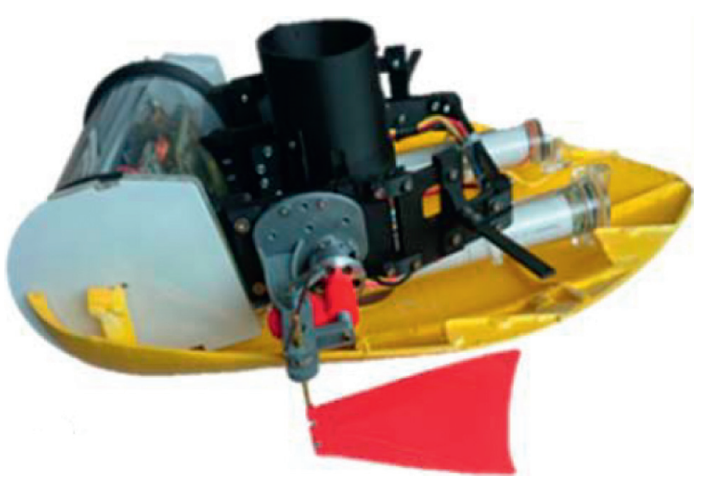

Figure 23: Bioinspired alternative shell and drive design (2016) [29]. 


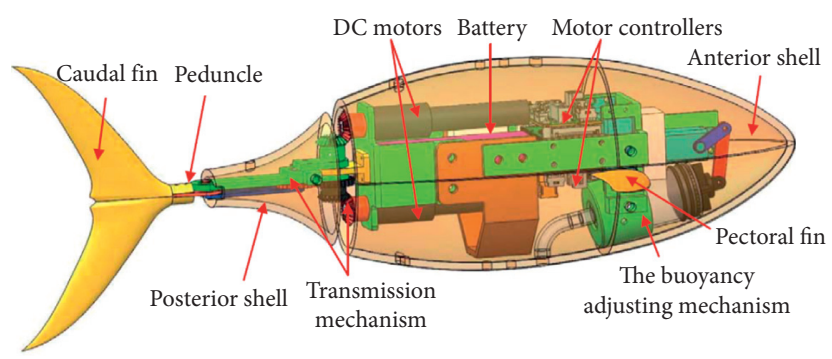

Figure 24: Almost tuna (2019) robot design [30].

TABLE 1: Characteristics of biomimetic robots.

\begin{tabular}{cccccc}
\hline Year & Name & Form & Propulsion & Dimension $(\mathrm{cm})$ & Material \\
\hline 2011 & RoboJelly & Jellyfish & Membrane & Not registered & Silicone, SMA, steel \\
2012 & TurtleLike & Turtle & Pectoral fins & Not registered & ABS, PDMS, SMA \\
2016 & Dolphin & Killer whale & Tail fin & $77.1 \times 13.2 \times 35.2$ & POM, fiberglass \\
2016 & Nameless & Shark & Tail fin & $48.3 \times 20.8 \times 12.5$ & ABS, rubber, aluminum \\
2016 & Nameless & Snake & Stern thruster/tunnel thruster/articulated swimming & Not registered & Not registered \\
2019 & OpenRov & Fish & Pair of propellers and fin & Not registered & PLA, varnish \\
2019 & CasiTuna & Tuna & Tail fin & $52.0 \times 10.0 \times 13.0$ & ABS, PP \\
\hline
\end{tabular}

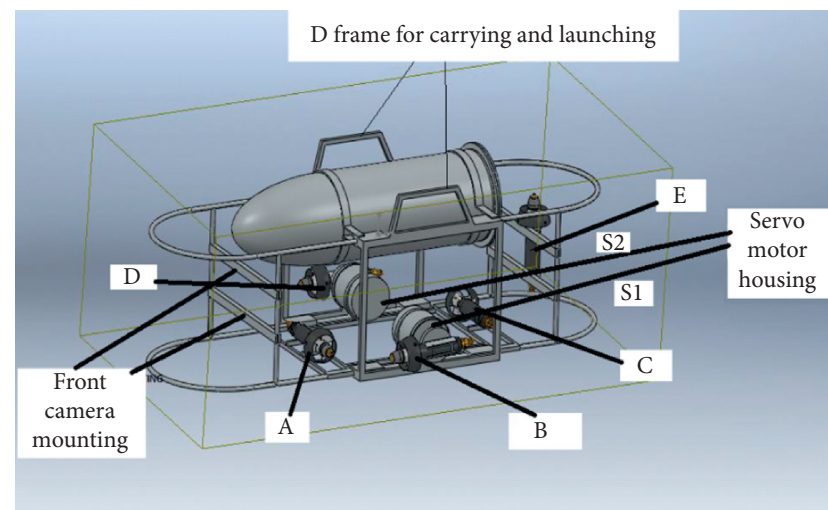

Figure 25: 5 thrusters [31].

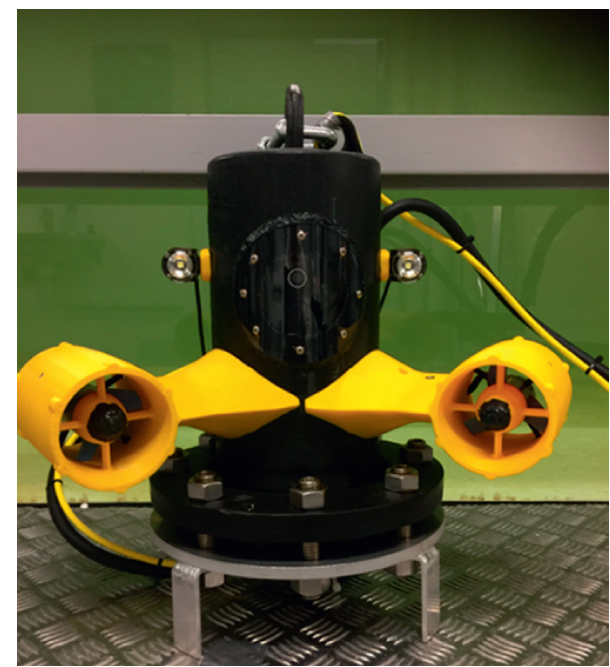

Figure 26: 3 thrusters [32].

\section{Materials and Hermeticity}

The material selected for an ROV manufacturer must withstand the pressure to which it is going to be subjected; the deeper the robot reaches, the greater the external pressure is during the robot's operation. The robots that have a torpedo shape as [9] are made of aluminum, with chambers filled with pressure air, and their frontal sections are made of plastic, such as the REMUS robot. There are more robots with torpedo shape; an example is Nessie [10], which was built externally with aluminum, and the internal structure was made of PVC to support some parts, such as sensors. Nessie's distribution is shown in Figure 32.

In 2016, a robot that had a hermetic chamber made of acrylic and PVC was proposed [34]; the acrylic part was placed in front of the camera to record outside and its thrusters supports were $3 \mathrm{D}$ printed. Figure 33 shows the parts. Another robot that had some of its parts 3D printed was introduced in [15]. The parts are in Figure 9. The 3D printer was an enormous advantage to the robot fabrication because the thrusters can save space due to better distribution; also, the mechanical fasteners are designed in a better way by $3 \mathrm{D}$ printing, and the mechanical resistance is better compared to the other propulsion system of the robot's water jets. One way to reduce the fabrication cost is using 3D print; the prototype [32] was an investigation project of an ROV in which the thrusters shell was $3 \mathrm{D}$ printed, and most of its structural parts were made of PE (polyethene) and PMMA (polymethylmethacrylate) to allow the camera recording.

One of the most important aspects taken into account in the manufactured material of the ROVs is the density; since materials with low density make the buoyancy increase in proportion to its weight, this means that more force is 


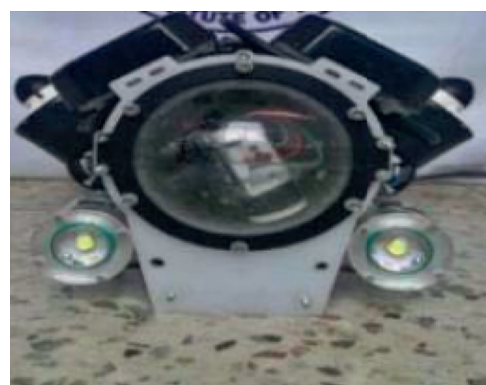

(a)

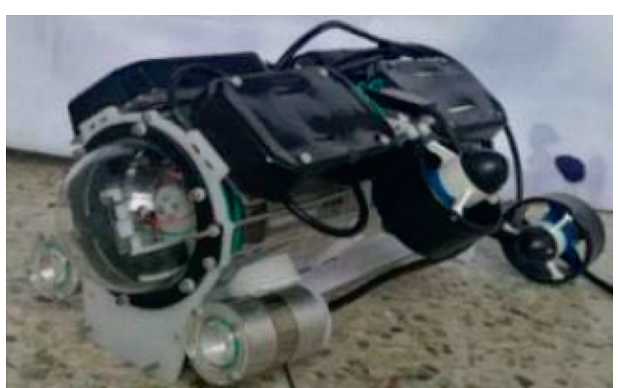

(b)

Figure 27: 4 assembled thrusters [33].

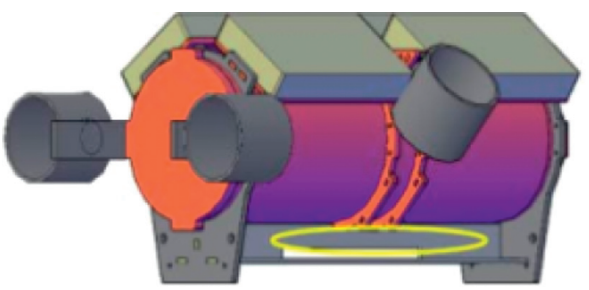

(a)

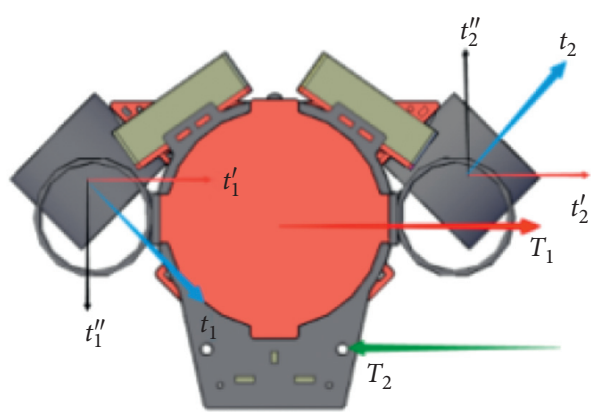

(b)

Figure 28: 4 thrusters [33].

required to submerge the robot. The underwater robot investigation [30] focused on its structural design where a 6036T6 aluminum alloy was selected for the structure supported motors and other $1 \mathrm{~cm}$ diameter elements; hence, the hermetic chamber was made of AL5053. Within the aforementioned robot's design, deformation analysis was made when the hermetic chamber was exposed to the pressure under the sea and the deformation of its supports.

Another prototype designed for aquaculture was introduced in [33]; the design had a hermetic chamber made of acrylic with a width of $5 \mathrm{~cm}$. The hermetical chamber's material beside the features mentioned above should have good corrosion resistance as mentioned in the design of [21]. The design proposed a hermetic chamber made of aluminum alloy 4032-T6 and in the forepart an acrylic dome was installed for the camera. There is a kind of underwater robot that uses something called biomimetics to move underwater and it is made of different materials, for example, a dolphin structure [26] made of fibreglass and the rest of the body made of paraformaldehyde (POM); this material has lightweight features. Another structure's robot is a shark
[27] which was made of ABS (acrylonitrile butadiene styrene), with an impermeable system that used o-rings of fluoride rubbers and Glyd Ring for dynamic sealing; further the posterior thrust part was connected to the mobile joints by a skeleton made of aluminum.

CasiTuna robot [30] was similar to the shark with an anterior and posterior body made of ABS, but this prototype had a flow fin made of PP (polypropylene). Another shape of this kind of robot is a turtle [22]; its body was of ABS and the head of PDMS (polydimethylsiloxane) and the structure fin was a combination between ABS and SMA (shape memory alloy). OpenROV robot bioinspiration came from a shell [29] and an alternative thruster made of PLA with a 3D printer, a further fillin process, varnish, and sanding to get a smooth surface.

There are a wide variety of shapes for this class of robots. As an example, there was a robot called RoboJelly [22] and it had a bell matrix structure made of silicon and 8 BISMAC actuators formed by a steel spring, silicone, and SMA wires. Table 2 shows the main features of the aquatic robots discussed in this section.

\section{Instrumentation and Actuators}

If we refer to the number of external devices, we should know that these increase or decrease with the arrival of new applications for unmanned aquatic robots. Mainly these are divided into two types: autonomous robots and AUVs (autonomous underwater vehicles) and ROVs (remotely operated vehicles), which also are divided by the type of application that they develop, such as intervention and inspection. The difference between these two classes lies in the different use of resources, size, and weight that the robot has in each division.

In this section, we will explain and focus on the use of instrumentation and actuators, collecting information from both types of unmanned robots.

\subsection{Sensors}

\subsubsection{Measurement of Oceanographic Variables}

(1) Temperature. To measure and process oceanographic variables in advanced systems, it is well known that the first relevant variable to be accounted for is the environmental 


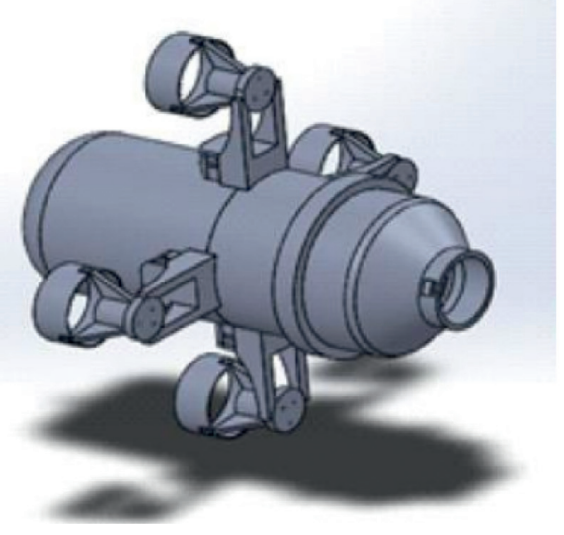

(a)

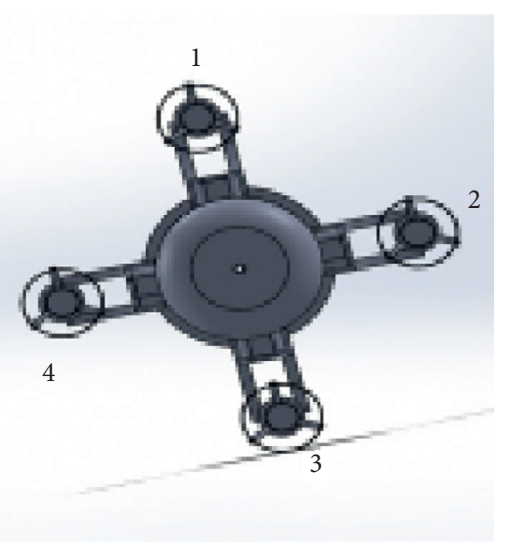

(b)

Figure 29: 4 thrusters located horizontally and vertically [34].

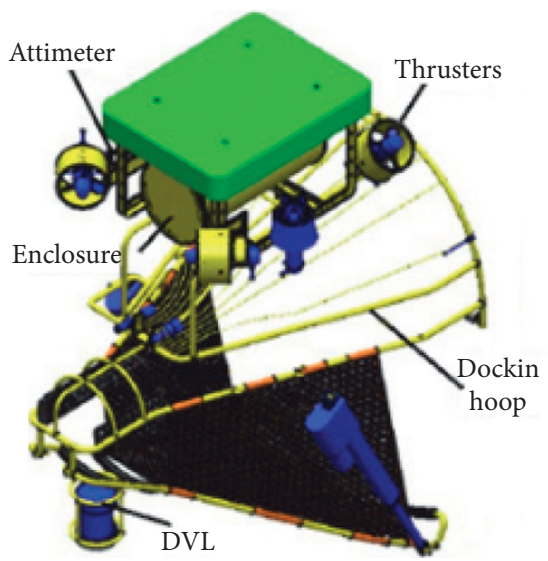

(a)

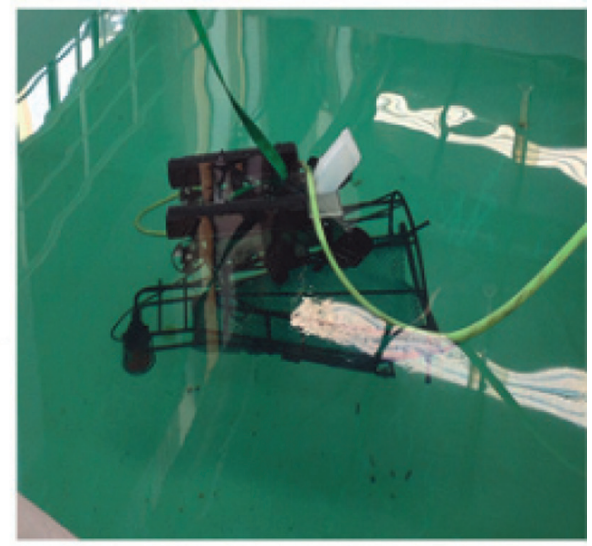

(b)

Figure 30: 6 thrusters [35].

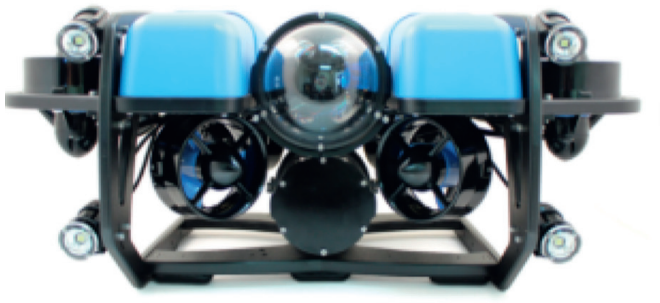

(a)

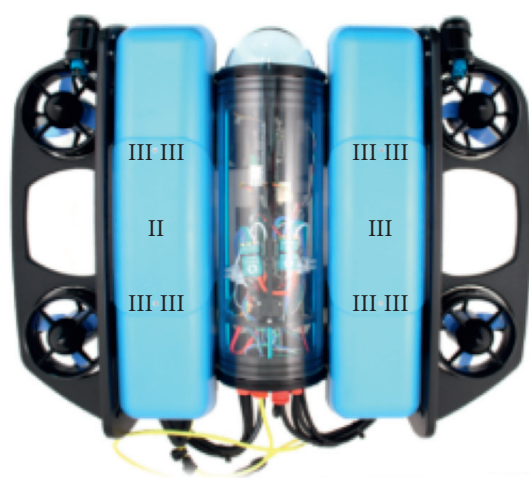

(b)

Figure 31: BlueROV2 and Bluerobotics' ROV with 8 thrusters [36].

temperature; this happens due to the changes in the temperature in the ocean, which not only influence the dynamics of the sea and the atmosphere but also intervene in the distribution of marine organisms and their metabolism; for this reason, some boats use a temperature sensor, which helps fishermen to set places and times propitious to fishing and also to know the distribution of fauna.

Likewise, sensors of depth, altitude, and temperature are always used in the design of aquatic robots. When we couple these 3 sensors, we will be able to obtain the data of 


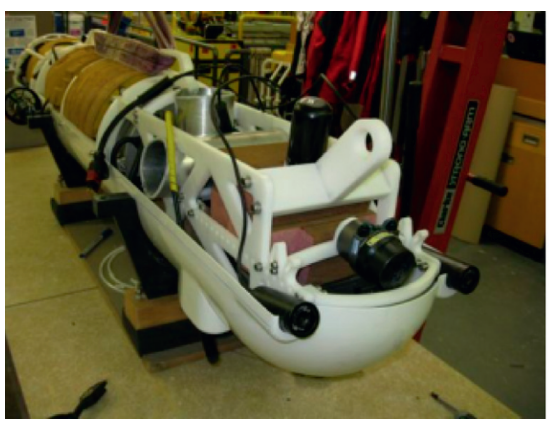

(a)

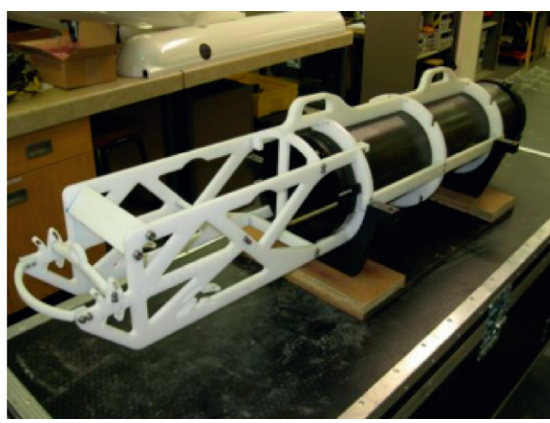

(b)

Figure 32: PVC frame [10].

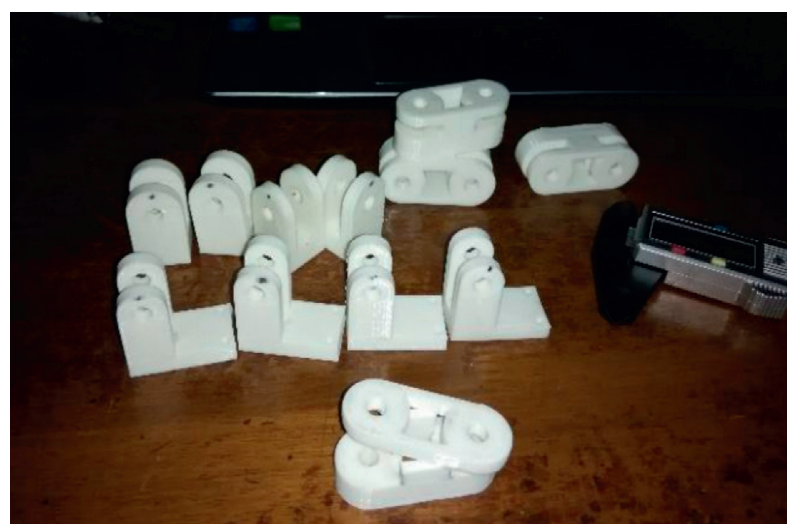

Figure 33: Printed thrusters mount [34].

oceanographic variables and the related variations between them. However, the measurement of the temperature sensor can be used not only to know better surroundings but also to compensate for the operation of the gyroscope and accelerometer [37]. That is the case of the UUV or SUR-II.

(2) Pressure. It is well known that the control of ballasts used in the stability of the structure of UUVs is directly related to the pressure sensors; this is due to the assembly of compressed air tanks, which are regulated by the constant variation of atmospheric pressure in the environment (symmetrical robots allow changing their center of gravity). This kind of behavior is observed with DaryaBird, a UUV that employs a YOKOGAWA's pressure sensor that measures depth and a gyroscope that measures the azimuth angle and altitude angle [19]. These two sensors help in the remote function, turning the UUV into an AUV (autonomous underwater vehicle) or in some cases it could help in turning it into a ROV that can be remotely operated; this type of UUV can recollect data and send it through an umbilical cable that reaches the surface to be visualized in a computer.

(3) Nitrate. The standard methods of obtaining oceanographic samples were through the samples collection with a single bottle, with the main tests being temperature, pressure, and salinity. In an advance to automation, "El Dorado" was presented in 2016, which is an AUV that recollects up to 10 shots of water in a bottle called "Gulper" [38]. El Dorado has sensors attached to its structure for reading chlorophyll and nitrate, where water samples can be used for the calibration of these parameters, as shown in Figure 34.

(4) Conductivity. Conductivity is the measurement of electrical resistivity, a property that quantifies how many dissolved substances, chemicals, and minerals are present in water. This means that a large amount of these impurities determines a higher conductivity. The use of CTD sensors allows water measurement of temperature, conductivity, and pressure. El Dorado AUV has a CTD sensor [38], which, like the SOTAB-I robot, is attached to its frame, with a sampling frequency of up to $16 \mathrm{~Hz}$ enabling a high spatial resolution, with a consumption of $3.4 \mathrm{~W}$ [39].

(5) Total ATP (adenosine triphosphate). There are some other kinds of sensors that ROVs have been carrying on recently; they are called microfluidics, which deal with the manipulation of concerning particles or droplets temporal dynamics, velocity, and spatial flow patterns in microchannels [40]; although it is a new multidisciplinary field, it has the potential to influence areas as biological analysis. They are also called LOC (lab on a chip) to be used as screen instruments in cell biology, chemical synthesis, and bioanalysis. They have some advantages because they are portable, and they can be done with low-cost fabrication materials. An example of an ROV is given below.

The total ATP is a useful biochemical parameter for detecting biomass or biochemical activity anomalies in the natural environment; since dissolved ATP is an important carbon and phosphorus for marine microbes is also related to microbial activity, the total ATP is a useful parameter indicative of the presence of biogeochemical events, such submarine volcanism, hydrocarbon seepages, and occasional supply of organic resources [41]. That is why, to obtain these variables in real time, a new version of an ATP analyzer was developed and evaluated in situ using an ROV, achieving a depth of $200 \mathrm{~m}$ in the tests carried out.

Figure 35 shows the analyzer; it has a microfluidic device and analyzer module, which is the core component, and a photometry module for the bioluminescence intensity measurements based on the $\mathrm{L}-\mathrm{L}$ reaction.

The measurements taken with the in situ ATP analyzer were consistent with those measured manually, which 
TABLE 2: Evaluated underwater robots features.

\begin{tabular}{|c|c|c|c|c|c|c|c|}
\hline Year & Name & Shape & Hull & Thrs & DoF & Dims $(\mathrm{cm})$ & Material \\
\hline 1973 & Snoopy & Torpedoes & Closed & NA & NA & Not registered & Not registered \\
\hline 1994 & REMUS & Torpedoes & Closed & 1 & 2 (roll, yaw) & $114.0 \times 18.0$ & Not registered \\
\hline 1997 & REMUS & Torpedoes & Closed & 1 & 2 (roll, yaw) & $134.0 \times 19.0$ & Aluminum \\
\hline 2011 & Nessie & Torpedoes & Closed & 6 & $5($ roll, yaw $, Y, Z, X)$ & $174.0 \times 28.0$ & Aluminum and PVC \\
\hline 2017 & Nameless & Torpedoes & Closed & 5 & $5($ roll, yaw, $Y, Z, X)$ & $534.0 \times 62.0$ & Not registered \\
\hline 2017 & Hybrid & Torpedoes & Closed & 4 & $4($ roll, yaw $, Y, Z)$ & $140.0 \times 20.0$ & Not registered \\
\hline 2012 & Nameless & Sphere & Closed & 3 & $3($ yaw $, Y, Z)$ & 40.0 & Acrylic \\
\hline 1966 & CURV & Rectangular & Open & NA & NA & Not registered & Not registered \\
\hline 2010 & Nessie IV & Rectangular & Open & 5 & 6 (pitch, roll, yaw, $Y, Z, X)$ & Not registered & Aluminum \\
\hline 2014 & CISCREA & Cubic & Open & 6 & $5($ roll, yaw, $Y, Z, X)$ & $52.2 \times 40.6 \times 39.5$ & Not registered \\
\hline 2016 & DayaBird & Rectangular & Open & 6 & $5($ roll, yaw, $Y, Z, X)$ & $80.0 \times 50.6 \times 41.3$ & Aluminum \\
\hline 2019 & Nameless & Rectangular & Open & 6 & 5 (pitch, yaw, $Y, Z, X)$ & Not registered & Aluminum and PVC \\
\hline 2019 & Nameless & Cubic & Open & 4 & $4($ roll, yaw, $Y, Z)$ & Not registered & Aluminum $4032-\mathrm{T} 6$ and acrylic \\
\hline 2015 & Nameless & Rectangular & Open & 5 & 6 (pitch, roll, yaw, Y, $Z, X)$ & $70.0 \times 40.0$ & Aluminum AL 5053 and $6036 \mathrm{~T} 6$ \\
\hline 2017 & Nameless & Cylinder & Closed & 3 & $3($ yaw $, Y, X)$ & $30.0 \times 20.0 \times 15.0$ & PPE and PMMA \\
\hline 2019 & Nameless & Cylinder & Closed & 4 & $5($ roll, yaw $, Y, Z, X)$ & $44.0 \times 26.0 \times 24.8$ & Acrylic \\
\hline 2019 & $\mathrm{X} 4-\mathrm{ROV}$ & Cylinder & Closed & 4 & $3($ yaw $, Y, X)$ & Not registered & PPVC and acrylic \\
\hline 2018 & BlueROV2 Heavy & Rectangular & Open & 8 & $6($ pitch, roll, yaw, $Y, Z, X)$ & $25.4 \times 57.5 \times 45.7$ & Aluminum and acrylic \\
\hline
\end{tabular}

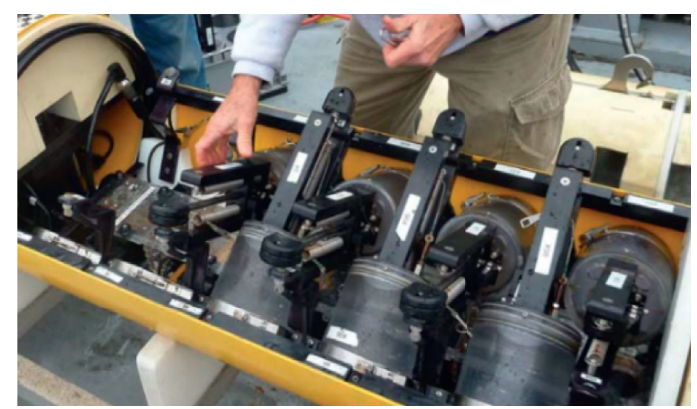

(a)

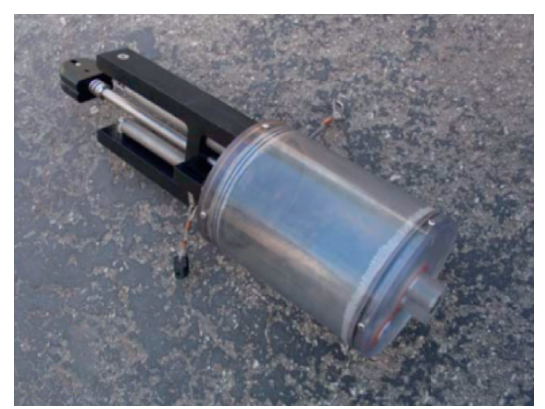

(b)

Figure 34: Images of El Dorado AUV, Gulper system [38].

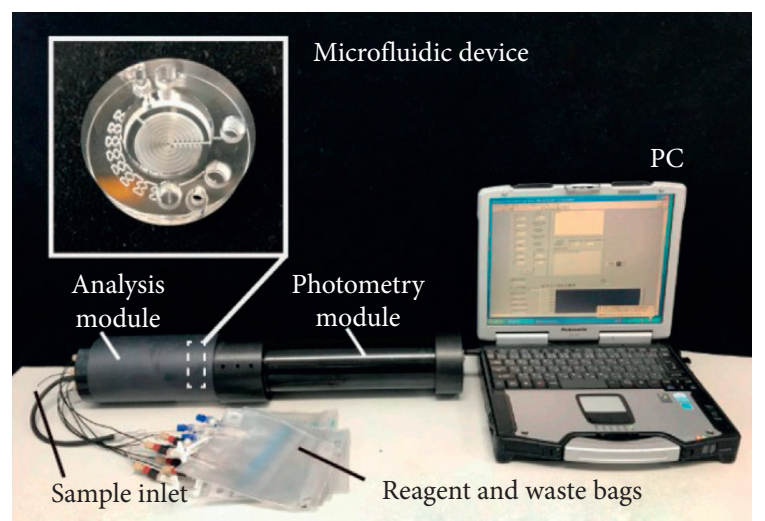

FIgURe 35: Total ATP analyzer with a microfluidic device [42].

demonstrated that a portable, simple, and reliable flow analysis system such as its microfluidic device can be used in extreme environments for real-time biochemical analyses.

4.1.2. Navigation Instruments. When the UUVs were built, different data acquisition methods were used such as position, direction, and speed. Also, the attitude and heading reference system (AHRS), the inertial navigation system (INS), or the hydroacoustic position reference (HPR) system was implemented to maintain better control of positioning and stability. The sensors that make up these systems and the applications in the different UVVs are described below.

(1) Inertial Sensors. The inertial measurement unit, better known as IMU, is a sensor that detects linear acceleration using one or more accelerometers, as well as the rotational speed using one or more gyroscopes. Some of these devices include a magnetometer that is used as the main reference.

In 2008, the ROV Nessie III was first introduced as an AUV that uses the 3-gyro reference system for navigation targets [43]. In 2010 AMOUR was introduced, which was a medium ROV destined for the investigation of maritime areas; this ROV used the coupling of an inertial sensor that estimates the position and depth that uses a record of 10 data raws unprocessed, corresponding to the sensors (a pressure sensor, 3 magnetic field sensors, 3 accelerometers, and 3 gyroscopes) [37]. On the other hand, MINERVA appeared in 2014, which was an intervention ROV that mixed two positioning systems and used an inertial sensor as the main 
sensor and a depth sensor [44]. This indicates that not only is a single-precision algorithm needed for navigation, but also other sensors are needed to compensate for the errors of a single system.

(2) Compass (Magnetometer). The magnetometer works by measuring the magnetic field variation in three referential axes that are subtracted from the Earth's magnetic field; despite its wide applications on the UUV development field, the operation of this sensor is sensitive to the noise caused by other sources like the operation of other sensors, motors, and others.

This means that you cannot only rely on the values of a magnetometer, as there are also several parts to be considered in underwater navigation such as a pressure sensor to measure depth, a gyroscope, and an accelerometer to control altitude and locomotion [45]. This also gives the solution of integrating dedicated digital sensors to increase the accuracy, modules that can evaluate the heading direction with a minimum difference of degrees, which are still compensated and calibrated to support magnetic distortions with the combination of other sensors, as is the case of a MEMS accelerometer 3-axis sensor and a 3-axis magnetoresistive sensor [46].

(3) GPS. The global positioning system is managed by direct communication with satellites; the use of these devices underwater does not allow their correct operation, so the best application to UUVs is through collection or recovery of these robots when they reach the surface.

The use is described by Choyekh Mahdi, indicating that the tracking of the SOTAB-I robot on the sea surface is ensured by a global positioning system (GPS) receiver that serves to determine the absolute position of the robot. In the case where the robot is submerged, the Ultrashort Baseline (USBL) system ensures tracking [39].

(4) Sonars. The sonar's performance is through sound, where the propagation of waves underwater allows navigation, communication, and detection of submerged objects. Since their use is standardized in underwater vehicles for operation in low-visibility conditions, there are a wide range of UUVs using this device; an example is Nessie III, which sent a specific signal from the vehicle to a transponder that responds; the delay in the vehicle that receives this response gives the bidirectional flight time for the signal; the range used was between $60 \mathrm{kHz}$ and $90 \mathrm{kHz}$ [43], and the result was to obtain the raw data of speed, distance, and distance time.

In 2017, the navigation compensation of an ROV was presented through the comparison of data extracted from a sonar with the use of the dead reckoning methodology and its compensated error [47], which details the use of the sonar when the ROV does not have any movement due to the interference that occurs with the operation of the engines, for its previous compensation. There are passive sonar systems, in which hydrophone-based communication participates in points not so far away between the robot and a boat or surface, giving sound pulses to find the distance between both objects and calculate the angle of the sound source. [19].
(5) Doppler Sonars. Doppler velocity sensor (DVS) uses the Doppler effect to measure the octagonal velocity; its limitations are based on the calculation of the integration of velocity and the time of calculating the position; this type of positioning control system will be explained in the next section; however, its operation can be up to $300 \mathrm{~m}$.

As mentioned before, MINERVA mixes two positioning systems, in which, apart from using an inertial sensor, it also uses the hydroacoustic positioning system through the use of a Doppler velocity record (DVL) to measure its velocity [44]. Figure 36 is an example of the calculated position through the use of a hydrophone array. This use is carried out in different UUVs, such as DaryaBird, which employs an altitude sensor TRAX [19], which was installed to control the movement in DVL sensors.

\subsubsection{Optic Sensors}

(1) Video Cameras. Most UUVs have standardized a complement of one video camera for transmission from depth to the surface; the images are important in environmental analysis. In 2010, in the construction of the TSL (Tunnel Sea Lion) robot, 2 video cameras were incorporated: one with a direct view on the bow and the other in a vertically downward orientation [48]. Likewise, another application to the mounted camera is to use it as a new addressing method by an AUV; this was observed in 2018 when tests were carried out on an interactive technique shown in Figure 37 which makes the construction of a coordinated system with a route drawn from the image taking through video [49].

Another application by the transmission of images was established in the detection of marine animals with varied visibility from a new dataset; video capture consists of three cameras and three lights. The colour cameras have a resolution of up to $1080 \times 1920$ pixels, and the frame rate is up to $30 \mathrm{fps}$ [50]; the camera direction is diagonally downward towards the riverbed.

4.2. Actuators. The underwater robot principle of movement is based on the use of propellers; the type, power, and weight of the motor used with these propellers depend on the robot's work, as explained at the beginning of the section.

\subsubsection{Engines and Thrusters}

(1) Water Jets. Among the variety of motors that we use to move the robot, we can find the propulsion based on a highpressure water jet. For a long time, this type of propulsion was normally used because of its comfortable design and its great propulsion with higher weights. In 2000, this type of propulsion was used in the development of a torpedoshaped robot called TSL, where the bow and stem propulsion systems had a tunnel for the performance of water jets [48].

In spherical-shaped AUVs, this type of drive is used in a vertical direction; two actuators can be controlled by one 


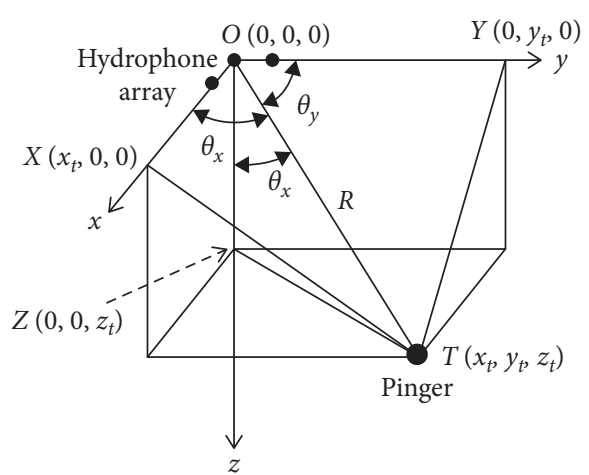

Figure 36: Acoustic detection plane [19].

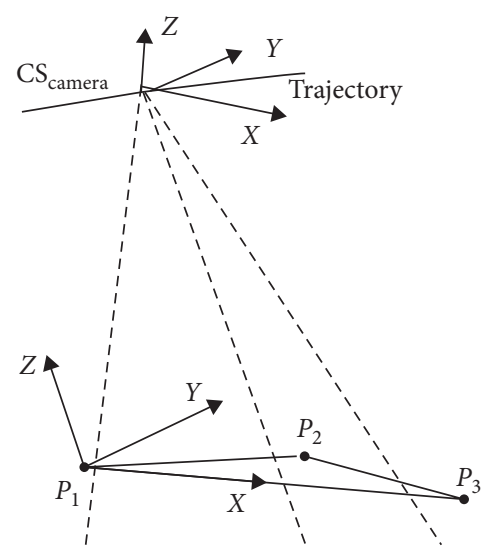

FIGURE 37: Construction of external orthogonal coordinate system [49].

thruster and one servomotor; the jet-based thruster decides the value of the driving force, and the servomotor controls the height of the thruster $[37,51]$.

(2) Stepper Motor. In the UUV's direction management, a form of steering management was introduced, which involved the torpedo structure (Xianbo et al., 2017); this structure has two propellers: one for horizontal movement and the other for vertical motion; these two are attached to the main propeller which is driven by a DC motor and four rudders driven by stepper motors [11].

(3) Brushes. Nessie III and DaryaBird used the same brush motor-based propeller offered by the SeaBotix brand, with a consumption of $110 \mathrm{~W}$ and an ability to withstand depth up to $150 \mathrm{~m}$; these were used in directional movement in the -xy plane; in the case of the second robot mentioned, it used a RoboPlus Hibikino thruster with a power of $90 \mathrm{~W}$ for the robot descent control.

(4) Servomotors. ARMOUR has a closed torpedo-shaped hull structure, which utilizes 10 propellers for handling 6 DOF (degrees of freedom); however, small spherical ROVs, such as SUR-II, use vector water jet thrusters composed of waterproof housing, two servomotors, and a support frame [37].
(5) Brushless. Brushless motors became popular in small and medium ROVs; their use dates back to the 80s and 90s. An example is ABE, an AUV destined for benthic species exploration that uses brushless motors (brushless) with oil [52] for pressure compensation. A clear example is ARMOUR, where each drive is made up of a motor controller and a brushless DC motor [53]. Another related example is the operation of Jeff, a small AUV designed for inspection and swarm joint work; the propulsion system has mainly two DC motors with a custom magnetic coupling design to avoid corrosion and short circuits. [45]

(6) Hydraulic Systems. In the design and development of UUVs, a new structure was chosen for the steering management in the 6-DOF; this particular configuration in parallel can be seen in Figure 38; it has two main thrusters in the front and another in the rear that handles the steering of the robot [54], and the union between the two parts is through the hydraulic system.

4.2.2. Luminaries. The functions performed by the UUVs include the inspection, manipulation, and data collection; all the robots have a video transmission system implemented, so it is necessary to develop a lighting system to acquire images since the underwater environment does not have visibility conditions due to the lack of a light source. The ROV system presented by Jinwoo uses two panoramic halogen lights and two LED lights to acquire high-quality images [55], as shown in Figure 39.

In another application in image acquisition, there are the recognition and detection of objects, for rescue or supervision robots, and a clear example of detection is found in the research of Pedersen et al., where the illuminated area is needed for the detection of pelagic species, where 3 LED lamps of 1900 lumens and an approximate resistance of 10 bar are used [50], to properly visualize the case study.

4.2.3. Manipulators. The term "manipulators" is used to describe a mechanical device with mobile joints intended for the manipulation of tools, parts, or special devices to perform various tasks. This meaning applied to robotics results in an automatic handling machine, reprogrammable in either a moving or fixed position. In 2011, a hybrid underwater robot was made, with a crab and lobster structure, where its legs acted as manipulators and its main function was to inspect underwater structures and shipwrecks in shallow waters, where activities such as cable cutting, grinding, and drilling are required [56].

The most common way to implement manipulators is in intervention class ROVs, for example, MINERVA, where its manipulator allows the samples collection. Table 3 summarizes all the aquatic robots seen in this section.

\section{Navigation and Control}

Navigation, in simple terms, conforms to particular methods that allow someone to know where they are and 


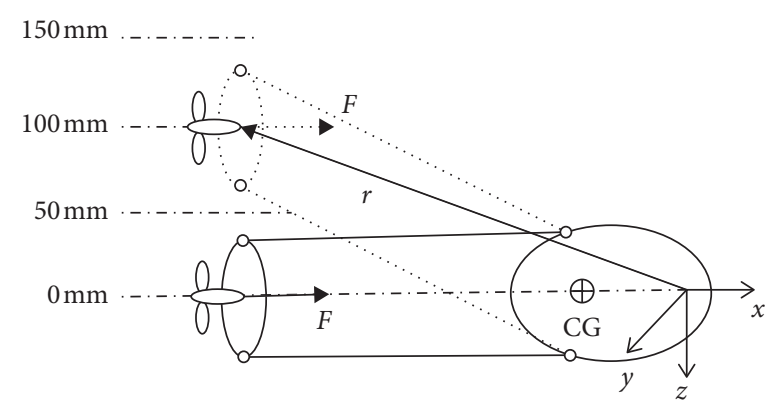

(a)

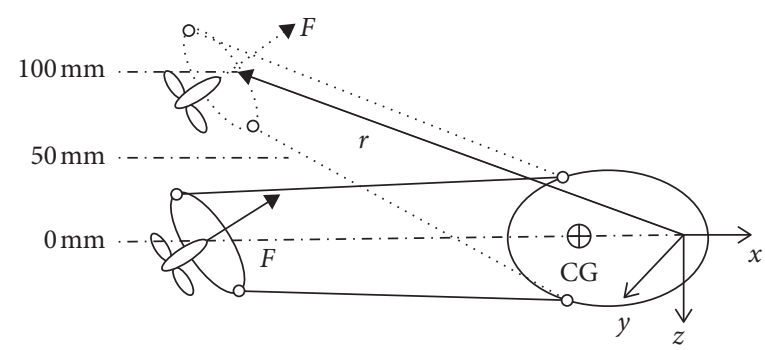

(b)

Figure 38: Direction change operation diagram [54].
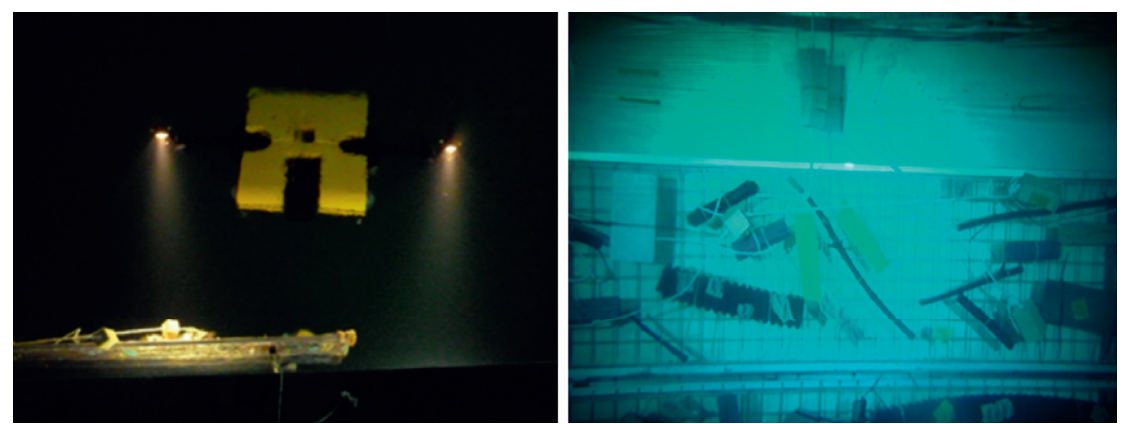

(a)
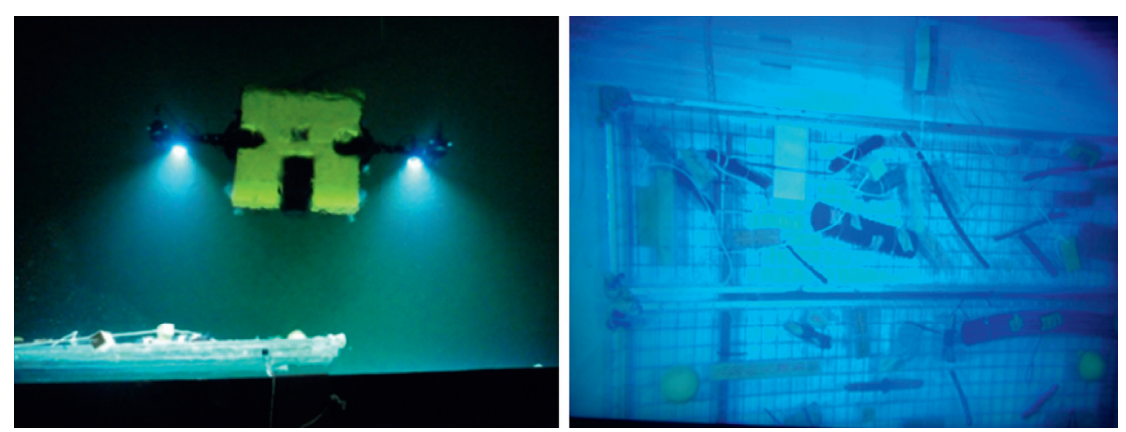

(b)

FIgURE 39: (a) The use of two LED lights. (b) The use of two halogen lights with their respective results [55].

how to get to a new point. Depending on the type of environment and available reference points, these methods could be simple; however, they could become complex results in a hostile, changing, and unpredictable environment, also, to reference points that are not visible [6]. The tasks that the UUVs must perform require navigation to displace to different location points to complete their duty. Navigation can be done by the vehicle itself (in the case of AUVs) or by operators (in ROVs cases). Usually, the tasks performed by ROVs demand heavy work and can be confined to smaller spaces where navigation is probably not very complex and could be performed directly by the operators through a joystick and the use of one or more video cameras installed on the ROV.

Moreover, autonomous vehicles have more tasks and must carry out missions that take several hours, days, or even months [57]. Most of these missions are focused on conducting maritime exploration which covers large areas of several hundred square kilometres. Navigation plays a vital role here that if it is not properly executed, it could not only affect the fulfilment of the mission but also affect the safety of the vehicle [11] and, in the worst scenario, could lead to the loss of the robot, causing economic loses and contamination of the explored environment. Due to its autonomy, navigation must be accomplished under the control of a computer embedded in the vehicle.

5.1. Navigation Methods. Navigation in AUVs represents a great challenge for most researchers due to the impossibility of using a global positioning system (GPS) underwater. The electromagnetic radiation waves emitted by satellites are absorbed when they come into contact with water, so a GPS signal receiver cannot capture the waves underwater [58]. 
TABLE 3: Summary of the evaluated UUVs.

\begin{tabular}{|c|c|c|c|c|}
\hline UUVs & ype & Application & Equipped sensors & Actuators \\
\hline ABE (1992) & AUV & Seabed supervision & $\begin{array}{c}\text { Compass, low-frequency sonar, angular } \\
\text { velocity sensor }\end{array}$ & $\begin{array}{l}3 \text { aft, } 2 \text { vertical and } 2 \\
\text { horizontal thrusters }\end{array}$ \\
\hline $\begin{array}{l}\text { Aqua Explorer } \\
1000(1992)\end{array}$ & AUV & $\begin{array}{l}\text { Inspection of telecommunication } \\
\text { signals and cables }\end{array}$ & $\begin{array}{l}\text { Gyroscope, altimeter, depth meter, } \\
\text { accelerometer, acoustic transponder }\end{array}$ & $\begin{array}{l}2 \text { horizontal thrusters, } 1 \\
\text { vertical with brushless } \\
\text { motor }\end{array}$ \\
\hline R1 (1995) & AUV & Monitoring near the seabed & $\begin{array}{l}\text { Depth gauge, CTDO sensor, INS with } \\
\text { Doppler sonar, acoustic transponder }\end{array}$ & $\begin{array}{c}\text { A main thruster, } 2 \text { vertical } \\
\text { water jet thrusters }\end{array}$ \\
\hline $\begin{array}{l}\text { MINERVA } \\
(2014)\end{array}$ & ROV & No register & a DVL, HPR and IMU & 5 thrusters \\
\hline $\begin{array}{l}\text { ARMOUR } \\
(2010)\end{array}$ & UUV & Reef survey and other applications & IMU, GPS, DVL & 5 thrusters \\
\hline$(2017)$ & URV & $\begin{array}{l}\text { Environmental study and } \\
\text { surveillance task in the mid-range of } \\
\text { shallow waters }\end{array}$ & $\begin{array}{l}\text { Depth sensor, leak sensor, camera, FOSN, } \\
\text { and mini-AHRS }\end{array}$ & $\begin{array}{c}4 \text { thrusters and an } 840 \mathrm{~W} \\
\text { main propeller }\end{array}$ \\
\hline $\begin{array}{l}\text { SUR } \\
(2013-2015)\end{array}$ & AUV & $\begin{array}{l}\text { Monitoring of nuclear storage ponds } \\
\text { and wastewater treatment facilities to } \\
\text { prevent leaks }\end{array}$ & No register & $\begin{array}{c}3 \text { servomotors and } 3 \text { water } \\
\text { jet propellers }\end{array}$ \\
\hline $\begin{array}{l}\text { REMUS I } \\
(2011)\end{array}$ & UPR & $\begin{array}{c}\text { Application of parallel robots in the } \\
\text { underwater environment requires } \\
\text { studies }\end{array}$ & $\begin{array}{l}\text { IMU, pressure sensor, immersion sensor, } \\
\text { temperature sensor, camera }\end{array}$ & $\begin{array}{l}\text { LED lights, } 1 \text { thruster at } \\
\text { the back }\end{array}$ \\
\hline TSL (2000) & AUV & Tunnel inspection & $\begin{array}{c}\text { GPS satellite navigation system, USBL } \\
\text { positioning system and autonomous on- } \\
\text { board navigation system, TV system, and } \\
\text { IFSSI scanning sonar }\end{array}$ & $\begin{array}{l}\text { Consists of six thrusters, } \\
\text { providing arbitrary } \\
\text { movements in } 3 \text { axes }\end{array}$ \\
\hline $\begin{array}{l}\text { Nessie III } \\
(2008)\end{array}$ & AUV & $\begin{array}{c}\text { Designed to participate in SAUC-E } \\
\text { competition }\end{array}$ & $\begin{array}{l}\text { Altimeter, IMU, camera, transponder, } \\
\text { battery temperature sensor }\end{array}$ & $\begin{array}{l}580 \mathrm{~W} \text { propellers, } \\
\text { brushless motors with oil }\end{array}$ \\
\hline$(2018)$ & AUV & $\begin{array}{c}\text { Check and evaluate new navigation } \\
\text { methods }\end{array}$ & Stereo camera, does not register other sensors & Does not register \\
\hline $\begin{array}{l}\text { DaryaBird } \\
(2016)\end{array}$ & AUV & Does not register & $\begin{array}{l}\text { Pressure sensor, DVL, USB camera, altitude } \\
\text { sensor, and hydrophone }\end{array}$ & $\begin{array}{l}4100 \mathrm{~W} \text { thrusters and } 2 \\
\text { main thrusters brushless } \\
\text { motors with oil. }\end{array}$ \\
\hline
\end{tabular}

Therefore, underwater devices have been used to establish a local positioning system. Thanks to advanced technology, many of these devices have been improved and optimized considerably in terms of dimensions and performance. This motivated the investigation and improvement of methods that allow a better estimation of the location and thus more exact navigation.

5.1.1. Proprioceptive Navigation. If the travel speed of the AUV is known, new positions can be estimated by consecutive integrations of speed. To perform velocity measures, Doppler velocity log (DVL) is normally used in conjunction with inertial systems and a compass; the estimated position solely depends on the movement of the vehicle and hence the proprioceptive name. This type of methodology is known as dead reckoning [59]. This type of navigation system corresponds to the research written by Itzik Klein and Roee Diamant; they developed a system that estimates the trajectory travelled by a water vehicle that moves freely in the direction of the marine currents [60]. Because these robots work very closely to the sea surface, they are easily susceptible to orientation change, which creates problems in the path. Through acceleration measures, the investigator can constrain the execution of a proposed algorithm based on the principal component analysis to calculate the acceleration in the vehicle's direction. If there is no need to execute the proposed algorithm, they use traditional dead reckoning to estimate the vehicle's heading direction and its position.

Another interesting work about accelerometers and how they are used corresponds to the authors Yan et al. [59]. They worked on a dead reckoning navigation system based on neural networks using only accelerometers, due to the cost of using other sensors such as a DL or the dependence on an acoustic system. The errors that have been generated by using inertial units are reflected in rapid changes in the measured angles by gyroscopes; this considerably increases the error of the dead reckoning system. The use of neural networks to estimate the pitch angles through an exploration between the measured orientations and the measured accelerations varying in time allows estimating the vehicle's positions and reducing the errors caused by the gyroscopes.

Normally, the proprietary navigation systems work in conjunction with external systems to correct themselves and reduce the accumulated error. Some of the work done on dead reckoning which works in conjunction with other reference systems corresponds [61] to Kepper et al. who developed a death reckoning model based on an inertial measurement unit (IMU), which works in conjunction with an acoustic measurement system to reduce the error accumulated by the IMU. Due to the noise generated by the 


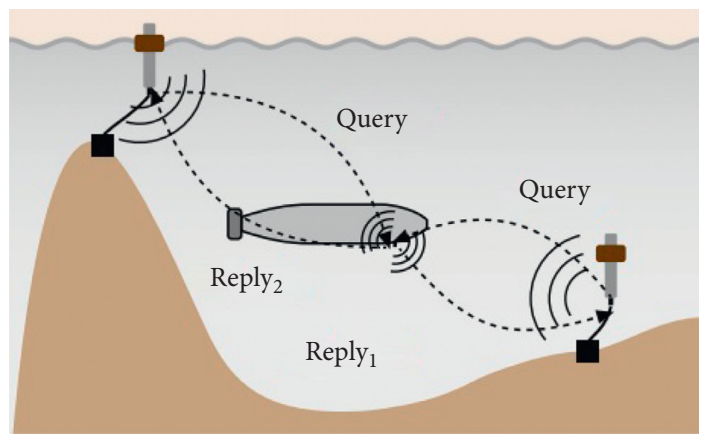

Figure 40: LBL standard mode [62].

IMU, the raw data captured was filtered using an extended Kalman filter. For the model effectiveness, implementation was evaluated in data collected in 3 different environments for field experiments and in an open ocean environment.

Correct navigation requires a good position estimate, so the instruments and the algorithms used must obtain the most exact ubication.

5.1.2. Acoustic Navigation. The main problem of proprioceptive navigation is that the error increases limitlessly as the distance travelled by the vehicle increases. If an external reference system is not considered, the navigation becomes critical for the vehicle and its mission. As a solution to this problem, acoustic navigation is employed. Acoustics waves are appropriate for underwater propagation due to minimal attenuation. Hence, they are employed for underwater communication and positioning the underwater vehicles. For example, underwater vehicles use data of the placed beacons for estimation of their positions in the work zone. The most used acoustics methods for underwater location are Long Baseline (LBL) and Ultrashort Baseline (USBL) [62].

The standard LBL method is characterized by beacons or transborder, which is fixed as shown in Figure 40. The image shows the configuration system for the vehicle and transponders.

First, transponders listen to the pings emitted for the vehicles, and distance estimation is obtained from TAT (turnaround time) at a specific frequency. Thus, the vehicle can estimate its position by algorithms based on recursive least squares (RLS) or using extended Kalman filters. The vehicle must save transponders positions.

Some works related to the implementation of an LBL system correspond to Christopher von Alt et al. Those who developed REMUS [8], a torpedo-shaped underwater robot created for exploration of marine resources, presented two modes of operation: autonomous and nonautonomous. In the autonomous mode, the robot had to follow a path formed by acoustic transponders implanted on the seabed, and REMUS acted as a target hunter. The transponders distribution defined the navigation path of REMUS; on the other hand, in the nonautonomous mode, the navigation was carried out with the help of a boat, and REMUS followed it through an acoustic communication.
This method works quite well for a single vehicle. In the case of the navigation with several vehicles, variants of this method have been proposed to eliminate the consultation signals, converting the communication in one direction and thus removing the dependence of the time intervals for vehicle location updates. However, both the beacons and the underwater vehicles must be synchronized [63].

The standard configuration of the LBL system and its variants (Figure 41) allows establishing an absolute positioning for either one or several underwater vehicles. However, the task of implementing and calibrating polygonal beacon arrangements is expensive and difficult. Therefore, it was decided to improve these systems even more and only one beacon has been achieved to determine the position of a vehicle; this system has been called Ultrashort Baseline (USBL). This configuration is illustrated in Figure 42 . This type of configuration works similarly to the standard LBL configuration; however, the vehicles have multiple acoustic receivers, because they must determine not only the distance at which they are from the beacon but also the angle with which the replica of the signal arrives. The query signal was issued. In this way, the need for using several beacons for the trilateration calculation is avoided. The vehicle's work area is confined to the entire radius generated by the beacon.

We can cite the work done by Hidaka et al. [19]. They implemented this acoustic navigation system which intended to use an array of hydrophones that were very close. The angle was calculated to the arriving sound from the offset that occurred between the hydrophones. Besides, the sonar system uses an electronic circuit for signal amplification, phase comparison, and digital to analog conversion (D/A).

5.1.3. Optical. Optical navigation uses optical devices such as video cameras or optical diodes from which morphological data of the seabed are recorded. M. Carreras et al. presented a localization approach for an underwater robot based on vision and in an environment structured like a water tank [64]. In the work, the location algorithm details through some graphic results and the precision of the system. The algorithm allows obtaining a 3D position, orientation, and speed of the vehicle by detecting reference points from the bottom of the tank. The location estimates are highly accurate without drift, allowing them to be used as feedback measurements for low-level speed-based controllers. Its computing system is $12.5 \mathrm{~Hz}$ in real time.

5.2. Orientation and Motion Control. It is necessary to take controlling the orientation and movement of underwater vehicles into account, and it may demand an exploration mission or some work that requires manipulation or extraction on the seabed. However, due to the presence of external disturbances and uncertainties in the marine environment, linear control methods are not very efficient, so it is necessary to apply advanced robust control methods. The objective of an orientation control is to retain the required orientation regardless of swell and unpredictable disturbances in the environment. That is why a hydrodynamic 


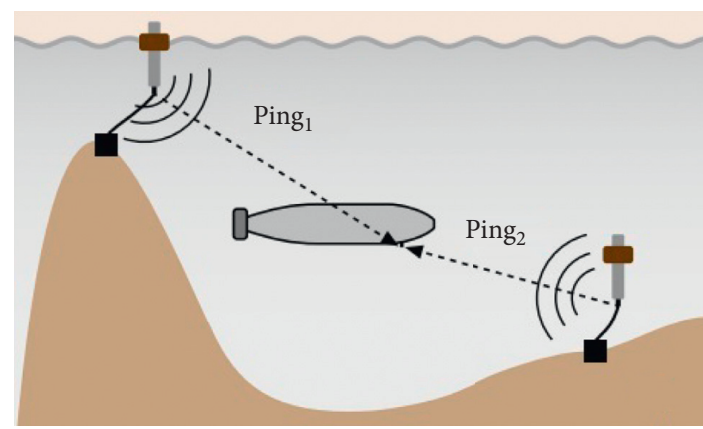

(a)

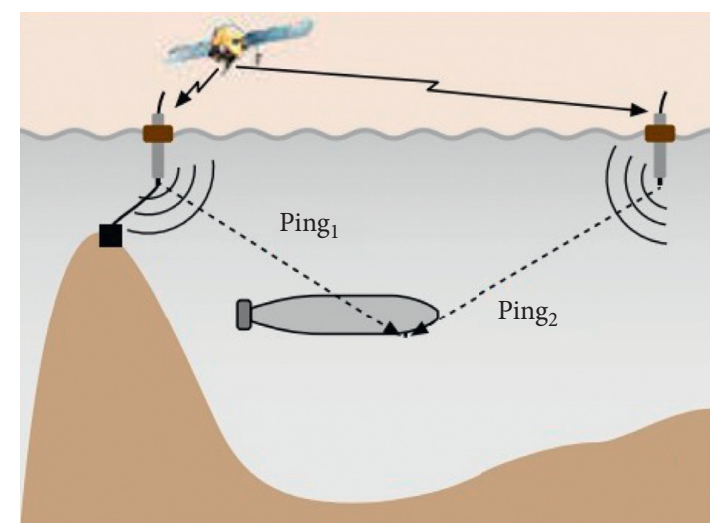

(b)

Figure 41: Variants of the standard LBL configuration. (a) An LBL configuration without query pings. (b) The configuration shown allows the beacons to obtain their locations using GPS [62].

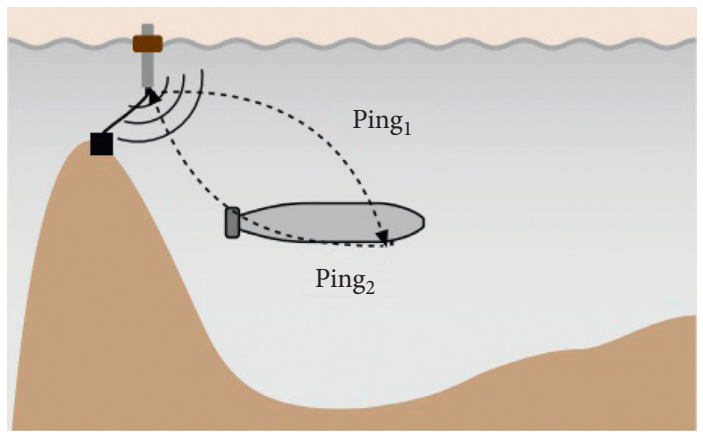

FIGURE 42: Ultrashort Baseline system [62].

model and mathematical parameters of the structure must be obtained first.

Likewise, to establish a control system, the following points must be taken into account: the performance of the system is limited, adding that the behavior of the control system must be robust in terms of both stability and performance, since it takes into account the energy management and optimization of the entire system [65]. This approach takes into account the inevitable imperfection in physical systems and variables; one of the investigations on the performance of a new control strategy for imperfect systems is observed in [66], starting from an electromechanical system based on a light structure that acts as a support and supply for the simple coils found in the structure; the purpose of this research is the simulation of control systems for imperfect systems that, thanks to the peculiar properties in the structure, the effects of vibration signals on the hidden dynamic system of the imperfect system can be observed.

Given the premise on nonlinear control systems in imperfect systems with more than two variables, it is considered that most of the research carried out within the field of hydrodynamics and the behavior of an ROV is established in only the movement controls, guaranteeing the movement of the robot in the established route without considering the dynamics hidden in the structure. However, most researchers make use of Computational Fluid Dynamics (CFD) simulations on the behavior of their framework to reduce the error due to changing environmental conditions which are difficult to predict.

5.2.1. Sliding Mode Control. The sliding mode control (SMC) is a robust control for modelling uncertainty and parameter variations and has good disturbance rejection characteristics. There have been a wide variety of applications of the same [67-71]. However, it inherits a discontinuous control action; therefore, the chattering phenomenon that occurs when the system operates close to the sliding surface will occur. Sometimes this discontinuous control action can even make system performance unstable.

5.2.2. Adaptive Control. Side Zhao and Junku Yuh proposed an adaptive control based on a disturbance observer $[69,72]$; the control scheme of this system has an adaptive controller based on a nonregressor, and it is the outer loop of the control scheme, while the inner loop controller is the disturbance observer. These two elements mentioned above are the components of the adaptive control system proposed by the authors, which is robust against external disturbances and unpredictable behaviors due to the self-adjustment of its 


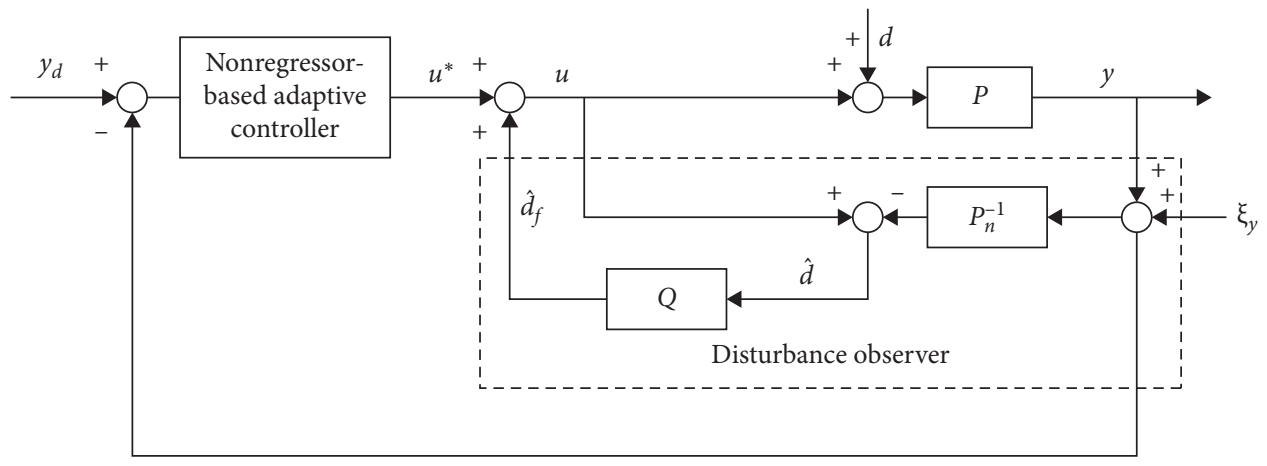

FIGURE 43: Diagram of the adaptive control system based on a disturbance observer [72].

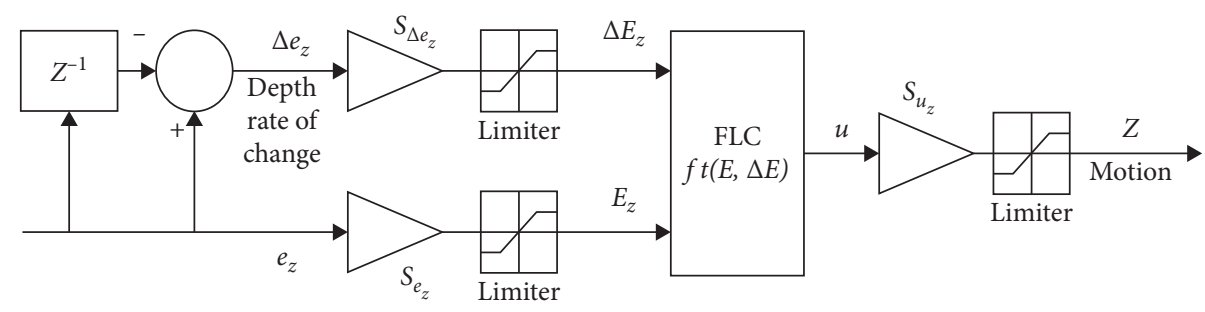

FIGURE 44: Fuzzy control system diagram for depth [74].

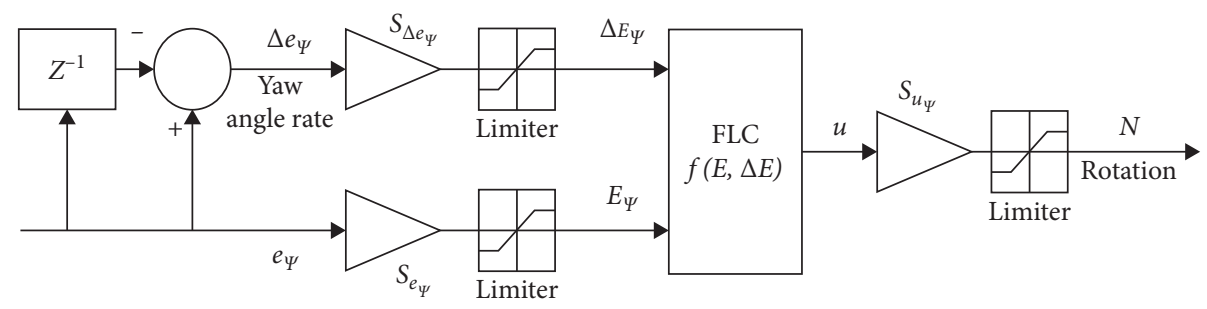

FIgURE 45: Fuzzy control system diagram for guidance [74].

TABLE 4: Classification of orientation and movement control methods most used in UUV.

Control methods Contribution of the method

(i) Path control in the horizontal and vertical plane in an AUV, using 6 degrees of freedom [77-79].

PID (ii) Integrated PID control with a backstepping control for trajectory control of an underactuated AUV [80].

(iii) Implementation of a self-adaptive fuzzy PID controller [81].

(iv) Proposal of a self-tuneable PID control, using neural networks [82].

(i) Avoid collision in marine vessels through an intelligent decision-making system [83].

Fuzzy (ii) Linear approximation control for tuning parameters of a fuzzy controller [84].

(iii) Features a torque controller, calculated with a trajectory compensation technique [85].

(iv) Adaptive fuzzy control for a multiple-input multiple-output (MIMO) system [86].

(i) Stabilize the motion control of an AUV disturbed by unknown hydrodynamic coefficients [87].

Adaptive (ii) Introducing an enhanced composite model reference adaptive control method to control AUV motion [88].

(iii) Adaptive control based on sliding mode control and fuzzy logic [89].

Sliding modes (i) Improved response, insensitive to parameter variation and disturbance [90-93].

Neural networks (i) A bioinspired neurodynamic model is presented, used for a kinematic controller [94].

(ii) Adaptive neural network controller combining hidden single-layer neural network and sliding mode control [95]. 
control parameters. They have implemented three controllers, PID, PID plus Dob, and the ADOB (adaptive controller based on a disturbance observer), to compare and evaluate the efficiency and performance, as shown in Figure 43.

5.2.3. Neural Networks. Recently, neural networks have gained considerable attention in robotic systems control due to their versatile properties, such as nonlinear mapping, learning ability, and parallel processing [67, 69, 73]. The most useful feature of neural networks in control is their ability to approximate arbitrary linear or nonlinear mapping through learning. Due to this property, neural networks have been proven to be a suitable tool to control complex nonlinear dynamic systems. However, due to their arithmetic complexity, their implementation in engineering is not easy.

5.2.4. Fuzzy Control. Control based on fuzzy logic or fuzzy control (FC) in English is a control that has supplanted conventional technologies in many applications $[35,68,74-76]$. An important property of fuzzy logic is its ability to express ambiguity in human thought. Therefore, when the mathematical model of the process does not exist or does exist with uncertainties, the FC becomes an alternative way for dealing with the unknown process. However, the large number of fuzzy rules for high-order systems makes the analysis complex. A fuzzy-based depth control scheme is illustrated in Figure 44 and a fuzzy-based yaw angle control scheme is illustrated in Figure 45.

Table 4 summarizes the main contributions of some additional navigation and orientation control methods that correspond to those most used by UUVs. In the first row of Table 4, some linear methods of proportional-integral-derivative (PID) type are included, which work in conjunction with the other previously reviewed methods.

\section{Conclusions}

The ROVs first shape was rectangular with an open hull and positive buoyancy; it was so big that it could not be transported by a single person, and it was necessary to place a pulley in the water. The torpedo-shaped underwater robot's design allowed robots to be faster during their underwater operation. Inside the investigated robots, it was found that only four thrusters provide 5 degrees of freedom compared to others that need six thrusters to reach 5 degrees. The studied robots determine that, to achieve all the degrees of freedom, the robots must have eight thrusters installed or five thrusters with two actuators to change the force direction. One of the most used materials in the manufacture of aquatic robots is aluminum, because it does not deform at high pressures; it is a dense material and is not corrosive. Most of the researches evaluated are designed to operate under positive buoyancy; to be able to submerge, they must activate the immersion thrusters; and to return to the surface it is enough that the thrusters are deactivated. The improvement of aerodynamic and hydrodynamic characteristics of aquatic robots with a biomimetic approach has accumulated great results, improving very important factors in the design such as hydrodynamic drag, propulsion force, and energy consumption, giving room to achieving better results with further study. It is important to mention that the biomimetic form of a robot not only implies improvements for itself but also reduces the degree of risk to possible alterations to a natural biological environment at the time of the interaction. The constant improvement of biomimetic technology has broken the trend of only implementing robots based on propulsion by caudal or pectoral fin; studies have opened a new window for the use of intelligent actuators, materials capable of providing better mechanical characteristics, such as greater flexibility under specific conditions, getting closer to the efficiency of real biological models with diverse morphological characteristics. The use of a pressure sensor has become much more standardized in the manufacture of any UUV, simply to obtain the depth data. However, some of these robots still have a dedicated depth sensor, thus achieving a greater comparison range between points. In most current ROVs, we can observe the constant use of an IMU sensor with the combination of sonar to find the underwater positioning, also applying a filter for the correct interpretation of data. GPS modules are used more in AUVs than in ROVs, because ROVs present a physical connection between the robot and controller, while the AUVs are programmed with a path or route to follow; that is why they emerge to the surface to obtain their position before making a submersion. The use of brushless motors has become very popular with the integration of propellers. It is found in different types of UUVs long before the 20th century. The advantage of this type of motor is adequate cost, better quality, and less maintenance than other motors. The application of new sensors for the acquisition of oceanographic data in robots has become increasingly common, as a result, mainly due to the growing interest in the study of marine ecosystems and the conservation of species. Many of the works reviewed, related to the control of direction or displacement with different engines, do not show much detail in the electronic components used, making it difficult to trace an evolutionary timeline of emerging technologies of electronic components used in UUVs. The methods and algorithms for navigating UUVs are mainly implemented in autonomous vehicles (AUVs). You can see the trend towards map-based navigation methods as opposed to those that use fixed beacons around their exploration environment. The orientation and movement control is applicable for both ROVs and AUVs, highlighting the routes control and trajectory tracking towards autonomous vehicles. The trend of new control methods is to apply combinations of more than one method to improve their characteristics and achieve finer control.

\section{Conflicts of Interest}

The authors declare that they have no conflicts of interest.

\section{Acknowledgments}

This research work is part of the project identified with the study BM-PNIPA-PES-SIADE-PP (No. 000027; Contract 
No. 256-2018), which is supported by PNIPA and World Bank. The authors thank companies MASTER PROVIDER and ACEMAR for help.

\section{References}

[1] J. E. Cohen, C. Small, A. Mellinger, J. Gallup, and J. Sachs, "Estimates of coastal populations," Science, vol. 278, no. 5341, pp. 1209-1213, 1997.

[2] J. Yuh, "Design and develop of an autonomous underwater vehicle: a survey," Autonomous Robots, vol. 8, no. 1, pp. 7-24, 2000.

[3] E. V. Lewis, "Principles of naval architecture," Seakeeping and Controllability, vol. 3, Society of Naval Architects \& Marine Engineers, Jersey City, NJ, USA, 1988.

[4] S. Chutia, N. M. Kakoty, and D. Deka, "A review of underwater robotics, navigation, sensing techniques and applications," in Proceedings of the Advances in Robotics, pp. 1-6, New Delhi, India, July 2017.

[5] B. K. Sahu and B. Subudhi, "The state of art of autonomous underwater vehicles in current and future decades," in Proceedings of the 2014 First International Conference on Automation, Control, Energy and Systems (ACES), pp. 1-6, IEEE, Adisaptagram, India, February 2014.

[6] R. B. Wynn, V. A. I. Huvenne, T. P. Le Bas et al., "Autonomous underwater vehicles (AUVS): their past, present and future contributions to the advancement of marine geoscience," Marine Geology, vol. 352, pp. 451-468, 2014.

[7] R. D. Christ, "The ROV manual a user guide for remotely operated vehicles," in The ROV Manual, pp. 57-58, IEEE, Piscataway, NJ, USA, 2014.

[8] C. von Alt, B. Allen, T. Austin, and R. Stokey, "Remote environmental measuring units," in Proceedings of the IEEE Symposium on Autonomous Underwater Vehicle Technology (AUV'94), pp. 13-19, IEEE, Cambridge, MA, USA, July 1995.

[9] B. Allen, R. Stokey, T. Austin et al., "Remus: a small, low cost AUV; system description, field trials and performance results," in Proceedings of the Oceans'97. MTS/IEEE Conference, pp. 994-1000, IEEE, Halifax, Canada, October 1997.

[10] M. Radojevic, M. M. Nawaf, F. Maurelli et al., Nessie VI Autonomous Underwater Vehicle, 2011, https://braincadet. com/papers/nessie11.pdf.

[11] X. Xiang, C. Yu, and Q. Zhang, "On intelligent risk analysis and critical decision of underwater robotic vehicle," Ocean Engineering, vol. 140, pp. 453-465, 2017.

[12] X. Ai, S. Kang, and W. Chou, "System design and experiment of the hybrid underwater vehicle," in Proceedings of the 2018 International Conference on Control and Robots (ICCR), Hong Kong, China, September 2018.

[13] G. Yao, J. Liang, T. Wang et al., "Development of a turtle-like underwater vehicle using central pattern generator," in Proceedings of the 2013 IEEE International Conference on Robotics and Biomimetics (ROBIO), Shenzhen, China, December 2013.

[14] X. Lin and S. Guo, "Development of a spherical underwater robot equipped with multiple vectored water-jet-based thrusters," Journal of Intelligent \& Robotic Systems, vol. 67, no. 3-4, pp. 307-321, 2012.

[15] S. Guo, Y. He, L. Shi et al., "Modeling and experimental evaluation of an improved amphibious robot with compact structure," Robotics and Computer-Integrated Manufacturing, vol. 51, pp. 37-52, 2018.

[16] Y. He, S. Guo, L. Shi, S. Pan, and Z. Wang, “3D printing technology-based an amphibious spherical robot," in Proceedings of the 2014 IEEE International Conference on
Mechatronics and Automation, pp. 1382-1387, IEEE, Tianjin, China, August 2014.

[17] F. Maurelli, J. Cartwright, N. Johnson, and Y. Petillot, "Nessie iv autonomous underwater vehicle wins the sauc-e competition," in Proceedings of the 10th International Conference on Mobile Robots and Competitions (ROBOTICA 2010), Leiria, Portugal, March 2010.

[18] R. Yang, B. Clement, A. Mansour, H. Li, M. Li, and N. Wu, "Modeling of a complex-shaped underwater vehicle," in Proceedings of the 2014 IEEE International Conference on Autonomous Robot Systems and Competitions (ICARSC), pp. 36-41, IEEE, Espinho, Portugal, May 2014.

[19] S. Hidaka, S. Kawashima, S. Nam et al., "System design and hardware development of autonomous underwater robot "daryabird," in Proceedings of the AUVSI\&ONR's 18th Annual RoboSub Competition Journal Paper, San Diego, CA, USA, July 2015.

[20] E. H. Binugroho, B. Setyawan, R. S. Dewanto, D. Pramadihanto et al., "Static and dynamic analysis of erov mechanical design using CFD," in Proceedings of the 2019 International Electronics Symposium (IES), pp. 628-632, IEEE, Surabaya, Indonesia, September 2019.

[21] Z. Yunhui, S. Lina, Q. Lu, and F. Qiang, "The frame structure of underwater Robot for shallow water," in Proceedings of the 2019 International Conference on Precision Machining, Nontraditional Machining and Intelligent Manufacturing (PNTIM 2019), Atlantis Press, Xi'an, China, September 2019.

[22] W.-S. Chu, K.-T. Lee, S.-H. Song et al., "Review of biomimetic underwater robots using smart actuators," International Journal of Precision Engineering and Manufacturing, vol. 13, no. 7, pp. 1281-1292, 2012.

[23] S.-H. Ahn, K.-T. Lee, H.-J. Kim, R. Wu, J.-S. Kim, and S.-H. Song, "Smart soft composite: an integrated 3D soft morphing structure using bend-twist coupling of anisotropic materials," International Journal of Precision Engineering and Manufacturing, vol. 13, no. 4, pp. 631-634, 2012.

[24] W.-S. C. Hyung-Soo Kim, J.-Y. Lee, and S.-H. Ahn, "Design and fabrication of soft morphing ray propulsor: undulator and oscillator," Soft Robotics, vol. 4, no. 1, pp. 49-60, 2016.

[25] F. Cairone, S. Gagliano, D. C. Carbone, G. Recca, and M. Bucolo, "Micro-optofluidic switch realized by 3D printing technology," Microfluid and Nanofluidics, vol. 20, 2016.

[26] J. Liu, Z. Wu, and J. Yu, "Design and implementation of a robotic dolphin for water quality monitoring," in Proceedings of the 2016 IEEE International Conference on Robotics and Biomimetics (ROBIO), pp. 835-840, IEEE, Qingdao, China, December 2016.

[27] X. Yang, Z. Wu, and J. Yu, "Design and implementation of a robotic shark with a novel embedded vision system," in Proceedings of the 2016 IEEE International Conference on Robotics and Biomimetics (ROBIO), pp. 841-846, IEEE, Qingdao, China, December 2016.

[28] J. Sverdrup-Thygeson, E. Kelasidi, K. Y. Pettersen, and J. T. Gravdahl, "The underwater swimming manipulator-a bio-inspired AUV," in Proceedings of the 2016 IEEE/OES Autonomous Underwater Vehicles (AUV), pp. 387-395, IEEE, Tokyo, Japan, November 2016.

[29] F. Hoffmann and A. B. Kesel, "Biologically inspired optimization of underwater vehicles hull geometries and fin propulsion," in Proceedings of the OCEANS 2019, pp. 1-4, IEEE, Marseille, France, June 2019.

[30] S. Du, Z. Wu, J. Wang, S. Qi, and J. Yu, "Design and control of a two-motor-actuated tuna-inspired robot system," IEEE Transactions on Systems, Man, and Cybernetics: Systems, 2019. 
[31] H. Saha and Parhi, "Conceptual design of an underwater robot," in 2015 International Conference on Man and Machine Interfacing (MAMI), pp. 1-6, IEEE, Bhubaneswar, India, December 2015.

[32] O. L. Osen, R.-I. Sandvik, V. Rogne, and H. Zhang, "A novel low cost rov for aquaculture application," in Proceedings of the OCEANS 2017, pp. 1-7, IEEE, Anchorage, Scotland, June 2017.

[33] M. Yang, Z. Sheng, Y. Che, J. Hu, K. Hu, and Y. Du, "Design of small monitoring rov for aquaculture," in Proceedings of the OCEANS 2019, pp. 1-9, IEEE, Marseille, France, June 2019.

[34] Z. M. Zain, M. M. Noh, K. A. Ab Rahim, and N. Harun, "Design and development of an X4-ROV," in Proceedings of the 2016 IEEE International Conference on Underwater System Technology: Theory and Applications (USYS), pp. 207-211, IEEE, Penang, Malaysia, December 2016.

[35] C. S. Chin and W. P. Lin, "Robust genetic algorithm and fuzzy inference mechanism embedded in a sliding-mode controller for an uncertain underwater robot," IEEE/ASME Transactions on Mechatronics, vol. 23, no. 2, pp. 655-666, 2018.

[36] R. Jehangir, Bluerov2 Heavy Configuration, Seascape Subsea B.V., Sleeuwijk, Netherlands, 2018.

[37] C. Yue, S. Guo, M. Li, Y. Li, H. Hirata, and H. Ishihara, Mechatronic System and Experiments of a Spherical Underwater Robot: SUR-II, Springer Science+Business Media, Dordrecht, Netherlands, 2015.

[38] F. C. J. T. Pennington and M. Blum, "Seawater sampling by an autonomous underwater vehicle: "gulper" sample validation for nitrate, chlorophyll, phytoplankton, and primary production," Limnology and Oceanography: Methods, vol. 14, no. 1, pp. 14-23, 2016.

[39] M. Choyekh, "Development and operation of underwater robot for autonomous tracking and monitoring of subsea plumes after oil spill and gas leak from seabed, and analyses of measured data," Doctoral thesis, Osaka University Knowledge Archive, School of Engineering Osaka University, Osaka, Japan, 2016.

[40] F. Sapuppo, F. Schembri, L. Fortuna, and M. Bucolo, "Microfluidic circuits and systems," IEEE Circuits and Systems Magazine, vol. 9, no. 3, pp. 6-19, 2009.

[41] T. Fukuba, T. Noguchi, K. Okamura, and T. Fujii, "Adenosine triphosphate measurement in deep sea using a microfluidic device," Micromachines, vol. 9, no. 8, 2018.

[42] F. S. Florinda Schembri and M. Bucolo, "Experimental classification of nonlinear dynamics in microfluidic bubbles' flow," Nonlinear Dinamics, vol. 4, pp. 2807-2819, 2012.

[43] A. Limanes, J. Cartwright, B. Davis et al., Nessie III Autonomous Underwater VehicleHeriot-Watt University, Scotland, UK, 2008.

[44] M. B. Bo Zhao, S. Roger, and F. Dukan, "Particle filter for fault diagnosis and robust navigation of underwater robot," Transactions on Control Systems Technology, vol. 22, no. 6, 2014.

[45] S. Mintchev, E. Donati, S. Marrazza, and C. Stefanini, Mechatronic Design of a Miniature Underwater Robot for Swarm Operations, Hong Kong Convention and Exhibition Center, Hong Kong, China, 2014.

[46] A. Jebelli, M. Yagoub, and B. Dhillon, "Design and control of underwater robots with rotating thrusters," IAES International Journal of Robotics and Automation, vol. 5, no. 4, pp. 284-294, 2016.

[47] G. Y. M. Dong and W. Chou, "A new navigation strategy for underwater robot in reactor pool combined propeller speed detection and dynamics analysis with sonar data correction,"
Journal of Nuclear Science and Technology, vol. 55, no. 3, pp. 1-10, 2017.

[48] M. D. Ageev, A. A. Boreyko, V. E. Gornak et al., "Modernized TSL-underwater robot for tunnel and shallow-water inspection," Institute for Marine Techonology Problems FEB RAS, Vladivostok, Russia, 2000.

[49] V. Bobkov, M. Sporyshev, and A. Scherbatyuk, "Evaluation of the effectivenes of the visual navigation technique for an autonomous underwater vehicle," in Proceedings of the 2018 OCEANS-MTS/IEEE Kobe Techno-Ocean (OTO), IEEE, Kobe, Japan, May 2018.

[50] M. Pedersen, J. Bruslund, R. Gade, and T. Moeslund, "Detection of marine animals in a new underwater dataset with varying visibility," in Section of Biology and Enviromental ScienceAalborg University, Aalborg, Denmark, 2019.

[51] C. Yeng, S. Guo, L. Shi, and J. Du, "Characteristics evaluation of the vertical motion of a spherical underwater," in Proceeding of the 2012 IEEE International Conference on Robotics and Biomimetics, Guangzhou, China, December 2012.

[52] B. W. D. R. Yoeger and A. M. Bradley, The Autonomous Benthic explorer (ABE): an AUV Optimized for Deep Seafloor Studies, Woods Hole Oceanographic Institution, Dept. of Applied Ocean Physics and Engineering, Falmouth, MA, USA, 1991.

[53] M. Doniec, I. Vasilescu, C. Detweiler, and D. Rus, "Complete SE3 underwater robot control with arbitrary thruster configurations," in Proceedings of the 2010 IEEE International Conference on Robotics and Automation Anchorage Convention District, p. 6, IEEE, Anchorage, AL, USA, May 2010.

[54] R. Saltaren, C. Garcia, C. Alvarez, and R. Aracil, "Experiences and results from designing and developing a 6 DOF underwater parallel robot," Robotics and Autonomous Systems, vol. 59, no. 2, pp. 101-112, 2010.

[55] J. Choi, T. Lee, T. Kim, J. Jung, and H. Choi, "Development of a ROV for visual inspection of harbor structures," in Proceedings of the 2017 IEEE Underwater Technology (UT), Busan, South Korea, February 2017.

[56] P. L. B. Jun and H. Shim, "Approximated generalized torques by the hydrodynamic forces acting on legs of an underwater walking robot," in International Journal of Ocean System Engineering, vol. 1, no. 4, pp. 222-229, IEEE, 2011.

[57] K. P. Valavanis, D. Gracanin, M. Matijasevic, R. Kolluru, and G. A. Demetriou, "Control architectures for autonomous underwater vehicles," IEEE Control Systems Magazine, vol. 17, no. 6, pp. 48-64, 1997.

[58] Y. Zhang and L. Cheng, "A distributed protocol for multi-hop underwater robot positioning," in Proceedings of the 2004 IEEE International Conference on Robotics and Biomimetics, pp. 480-484, IEEE, Dali, China, December 2004.

[59] Z. Yan, S. Peng, J. Zhou, J. Xu, and H. Jia, "Research on an Improved dead reckoning for AUV navigation," in Proceedings of the 2010 Chinese Control and Decision Conference, pp. 1793-1797, IEEE, Xuzhou, China, May 2010.

[60] I. Klein and R. Diamant, "Dead reckoning for trajectory estimation of underwater drifters under water currents," Journal of Marine Science and Engineering, vol. 8, no. 3, p. 205, 2020.

[61] J. H. Kepper IV, B. C. Claus, and J. C. Kinsey, "A navigation solution using a MEMS IMU, model-based dead-reckoning, and one-way-travel-time acoustic range measurements for autonomous underwater vehicles," IEEE Journal of Oceanic Engineering, vol. 44, no. 3, pp. 664-682, 2018.

[62] J. J. Leonard and A. Bahr, "Autonomous underwater vehicle navigation," in Springer Handbook of Ocean Engineering, pp. 341-358, Springer, Cham, Switzerland, 2016. 
[63] A. Alcocer, P. Oliveira, and A. Pascoal, "Study and implementation of an ekf gib-based underwater positioning system," Control Engineering Practice, vol. 15, no. 6, pp. 689-701, 2007.

[64] M. Carreras, P. Ridao, R. García, and T. Nicosevici, "Visionbased localization of an underwater robot in a structured environment," vol. 1, pp. 971-976, in Proceedings of the 2003 IEEE International Conference on Robotics and Automation (Cat. No. 03CH37422), vol. 1, pp. 971-976, IEEE, Taipei, China, September 2003.

[65] L. Fortuna, A. Buscarino, M. Frasca, and C. Famoso, "Chapter 1: imperfect uncertain systems," in Control of Imperfect Nonlinear Electromechanical Large Scale Systems, World Scientific Series on Nonlinear Science, Springer, Boston, MA, USA, 2017.

[66] M. Bucolo, A. Buscarino, C. Famoso, L. Fortuna, and M. Frasca, "Control of Imperfect dynamical systems," Nonlinear Dynamics volume, vol. 98, pp. 2989-2999, 2019.

[67] T. Chatchanayuenyong and M. Parnichkun, "Neural network based-time optimal sliding mode control for an autonomous underwater robot," Mechatronics, vol. 16, no. 8, pp. 471-478, 2006.

[68] S. Guo, J. Du, X. Lin, and C. Yue, "Adaptive fuzzy sliding mode control for spherical underwater robots," in Proceedings of the 2012 IEEE International Conference on Mechatronics and Automation, pp. 1681-1685, IEEE, Chengdu, China, August 2012.

[69] M.-j. Zhang and Z.-z. Chu, "Adaptive sliding mode control based on local recurrent neural networks for underwater robot," Ocean Engineering, vol. 45, pp. 56-62, 2012.

[70] S. Jin, J. Bak, J. Kim, T. Seo, and H. S. Kim, "Switching pdbased sliding mode control for hovering of a tilting-thruster underwater robot," PLoS One, vol. 13, no. 3, 2018.

[71] A. J. Healey and D. Lienard, "Multivariable sliding mode control for autonomous diving and steering of unmanned underwater vehicles," IEEE Journal of Oceanic Engineering, vol. 18, no. 3, pp. 327-339, 1993.

[72] S. Zhao and J. Yuh, "Experimental study on advanced underwater robot control," IEEE Transactions on Robotics, vol. 21, no. 4, pp. 695-703, 2005.

[73] M. Chen, B. Jiang, J. Zou, and X. Feng, "Robust adaptive tracking control of the underwater robot with input nonlinearity using neural networks," International Journal of Computational Intelligence Systems, vol. 3, no. 5, pp. 646-655, 2010.

[74] I. Akkizidis, G. Roberts, P. Ridao, and J. Batlle, "Designing a fuzzy-like pd controller for an underwater robot," Control Engineering Practice, vol. 11, no. 4, pp. 471-480, 2003.

[75] X. Xiang, C. Yu, and Q. Zhang, "Robust fuzzy 3d path following for autonomous underwater vehicle subject to uncertainties," Computers \& Operations Research, vol. 84, pp. 165-177, 2017.

[76] C. Yu, X. Xiang, L. Lapierre, and Q. Zhang, "Nonlinear guidance and fuzzy control for three-dimensional path following of an underactuated autonomous underwater vehicle," Ocean Engineering, vol. 146, pp. 457-467, 2017.

[77] I. Kaminer, A. Pascoal, E. Hallberg, and C. Silvestre, "Trajectory tracking for autonomous vehicles: an integrated approach to guidance and control," Journal of Guidance, Control, and Dynamics, vol. 21, no. 1, pp. 29-38, 1998.

[78] G. Antonelli, F. Caccavale, S. Chiaverini, and G. Fusco, "A novel adaptive control law for underwater vehicles," IEEE Transactions on Control Systems Technology, vol. 11, no. 2, pp. 221-232, 2003.
[79] W. Zhang, H. Wang, X. Bian, Z. Yan, and G. Xia, “The application of self-tuning fuzzy PID control method to recovering AUV," in Proceedings of the 2012 OCEANS, pp. 1-5, IEEE, Virginia Beach, VA, USA, October 2012.

[80] N. H. Z. M. Zain, "A backstepping based PID controller for stabilizing an underactuated X4-AUV," ARPN Journal of Engineering and Applied Sciences, vol. 10, no. 21, 2015.

[81] M. H. Khodayari and S. Balochian, "Modeling and control of autonomous underwater vehicle (AUV) in heading and depth attitude via self-adaptive fuzzy PID controller," Journal of Marine Science and Technology, vol. 20, no. 3, pp. 559-578, 2015.

[82] R. Hernández-Alvarado, L. G. García-Valdovinos, T. SalgadoJiménez, A. Gómez-Espinosa, and F. Fonseca-Navarro, "Neural network-based self-tuning PID control for underwater vehicles," Sensors, vol. 16, no. 9, p. 1429, 2016.

[83] L. Perera, J. Carvalho, and C. G. Soares, "Fuzzy logic based decision making system for collision avoidance of ocean navigation under critical collision conditions," Journal of Marine Science and Technology, vol. 16, no. 1, pp. 84-99, 2011.

[84] M. Aras, M. Shahrieel, H. I. Jaafar, and M. K. Anuar, “Tuning process of single input fuzzy logic controller based on linear control surface approximation method for depth control of underwater remotely operated vehicle," Journal of Engineering and Applied Sciences, vol. 8, no. 6, pp. 208-214, 2013.

[85] Y. Chen, R. Zhang, X. Zhao, and J. Gao, "Tracking control of underwater vehicle subject to uncertainties using fuzzy inverse desired trajectory compensation technique," Journal of Marine Science and Technology, vol. 21, no. 4, pp. 624-650, 2016.

[86] H. F. Ghavidel and A. A. Kalat, "Robust control for mimo hybrid dynamical system of underwater vehicles by composite adaptive fuzzy estimation of uncertainties," Nonlinear Dynamics, vol. 89, no. 4, pp. 2347-2365, 2017.

[87] H. R. Koofigar, "Robust adaptive motion control with environmental disturbance rejection for perturbed underwater vehicles," Journal of Marine Science and Technology, vol. 22, no. 4, pp. 455-462, 2014

[88] C. D. Makavita, H. D. Nguyen, D. Ranmuthugala, and S. G. Jayasinghe, "Composite model reference adaptive control for an unmanned underwater vehicle," Underwater Technology, vol. 33, no. 2, pp. 81-93, 2015.

[89] S. Pezeshki, A. Ghiasi, M. Badamchizadeh, and K. Sabahi, "Adaptive robust control of autonomous underwater vehicle," Journal of Control, Automation and Electrical Systems, vol. 27, no. 3, pp. 250-262, 2016.

[90] A. Bagheri and J. J. Moghaddam, "Simulation and tracking control based on neural-network strategy and sliding-mode control for underwater remotely operated vehicle," Neurocomputing, vol. 72, no. 7-9, pp. 1934-1950, 2009.

[91] D. Zhu and B. Sun, "The bio-inspired model based hybrid sliding-mode tracking control for unmanned underwater vehicles," Engineering Applications of Artificial Intelligence, vol. 26, no. 10, pp. 2260-2269, 2013.

[92] J. Xu, M. Wang, and L. Qiao, "Dynamical sliding mode control for the trajectory tracking of underactuated unmanned underwater vehicles," Ocean Engineering, vol. 105, pp. 54-63, 2015.

[93] Z. Chu and D. Zhu, "Adaptive sliding mode heading control for autonomous underwater vehicle including actuator dynamics," in Proceedings of the OCEANS 2016, pp. 1-5, IEEE, Shanghai, China, September 2016..

[94] B. Sun, D. Zhu, F. Ding, and S. X. Yang, "A novel tracking control approach for unmanned underwater vehicles based on 
bio-inspired neurodynamics," Journal of Marine Science and Technology, vol. 18, no. 1, pp. 63-74, 2013.

[95] J. Gao, P. Wu, B. Yang, and F. Xia, "Adaptive neural network control for visual servoing of underwater vehicles with pose estimation," Journal of Marine Science and Technology, vol. 22, no. 3, pp. 470-478, 2017. 